\title{
An integrated climate-biodiversity framework to improve planning and policy: an application to wildlife crossings and landscape connectivity
}

\author{
Robert Newell $^{1,2}$ Ann Dale $^{2}$ and Nina-Marie Lister ${ }^{3}$
}

\begin{abstract}
Planning and policy are best done through integrated approaches that holistically address multiple sustainability issues. Climate change and biodiversity loss are two of the most significant issues facing our planet. Accordingly, advancements in integrated sustainability planning and policy require a means for examining how certain strategies and actions may align or conflict with these sustainability imperatives. Here, we enhance the knowledge of integrated approaches for addressing sustainability challenges by developing and applying a framework for examining different planning and policy areas in the context of climate action and biodiversity conservation. As a case study, we used wildlife crossing planning and landscape connectivity policy in Canada, which is currently piecemeal, fragmented, and could benefit from an integrated approach. The study was conducted in two stages. First, we developed an analytical framework for examining issues in the context of climate action and biodiversity conservation co-benefits and trade-offs. Then, we applied the framework to wildlife crossing and landscape connectivity issues to elucidate opportunities and challenges for integrated planning and policy. We used a literature review to develop an integrated climate-biodiversity framework (ICBF). ICBF was subsequently applied to wildlife crossing and landscape connectivity planning and policies in Canada. ICBF maps relationships between climate action and biodiversity conservation co-benefits and trade-offs and is organized into six themes: green space, transportation, green infrastructure, food and agriculture, energy, and land management. Applying ICBF to participant interview data produced insights into opportunities and challenges for integrated approaches to wildlife crossing and landscape connectivity by elucidating potential co-benefits and trade-offs such as alignments between stormwater management and aquatic crossings (i.e., co-benefits) and potential issues related to energy development and habitat fragmentation (i.e., trade-offs). ICBF has application beyond wildlife crossings, and its continual use and refinement will result in a better understanding of how to effectively implement integrated approaches and transition toward sustainable development paths.
\end{abstract}

Key Words: biodiversity; climate change; integrated planning; landscape connectivity; sustainability; wildlife crossings

\section{INTRODUCTION}

Sustainable development involves the reconciliation of social, economic, and environmental imperatives (Dale 2001, Rydin 2010), which requires integrated approaches to planning that recognize how different actions, policies, and strategies link to broader goals for humans and the environment (Ling et al. 2009, Shaw et al. 2014, Dale et al. 2018). Such approaches can result in co-benefits; for example, densification and mixed-use development is a strategy for reducing sprawl and urban traffic, but it can also result in healthier communities by increasing local walkability (Newell and Picketts 2020). Equally important, integrated approaches can reveal trade-offs such as potentially competing land uses between agricultural development and habitat conservation (Turner et al. 2014). Applying an integrated lens to planning and policy enables a holistic understanding of how to approach a sustainability challenge, and it can reveal possible pathways for optimizing co-benefits while minimizing (or at least recognizing) the trade-offs.

Previous research on integrated planning and management has developed frameworks that define "dimensions of integration" (e.g., Sorensen 1997, Kelly et al. 2013). For example, Jakeman and Letcher (2003) identified dimensions of integrated natural resource assessment to include considerations of multiple issues and stakeholders, natural and social science disciplines, scales of representations and behaviors of systems, and spatially and temporally cascading effects. Although they are useful for obtaining high-level insights, these frameworks are often somewhat vague; for example, defining exactly what "multiple issues" means in different places and environmental contexts is nebulous and uncertain. Other integrated frameworks focus on planning domains such as water-energy-food, water-energy-foodenvironment, and water-food-energy-climate nexuses (Hellegers et al. 2008, Hoff 2011, Beck and Villaroel Walker 2013, Galderisi 2017). However, these frameworks define broad, vague areas of integration and are ambiguous in terms of how they are applied to planning and policy issues (Cairns and Krzywoszynka 2016).

An alternative approach to an analytical framework for investigating integrated planning and policy would be to specify and center on sustainability objectives and their intersections. Such a framework would provide an analytical lens for identifying best practices that holistically address sustainability imperatives. Developing such a framework first involves identifying the most critical sustainability issues facing communities locally and globally. Among these issues are climate change and biodiversity loss (Rockström et al. 2009, Steffen et al. 2015), confirmed by two major scientific reports from the Intergovernmental Panel on Climate Change (IPCC 2018) and Intergovernmental SciencePolicy Platform on Biodiversity and Ecosystem Services (IPBES 2019). IPCC (2018) warns that unless we engage in ambitious mitigation measures to limit warming to $1.5^{\circ} \mathrm{C}$ above preindustrial levels within the decade, we will face catastrophic changes to our environmental, economic, and social systems. Similarly, IPBES (2019) explains that species loss is accelerating to a rate of 10 s to 100 s of times faster than the average over the past 10 million years, and continued loss of biodiversity at this rate will have dramatic consequences for both natural and human 
systems viability. Engaging in climate action and biodiversity conservation to build social-ecological resilience and make progress toward sustainability is imperative (Collier et al. 2013); thus, climate and biodiversity objectives form essential components of a framework for integrated sustainability planning and policy.

Developing an analytical framework for examining issues through a climate-biodiversity lens requires understanding the supportive and conflicting relationships between climate action and biodiversity conservation strategies. In a broad sense, one can argue that all effective climate action strategies can indirectly benefit biodiversity because climate change is a major threat to global ecosystems (IPBES 2019). However, when looking at individual strategies, it is clear that not all climate mitigation approaches have appreciable biodiversity outcomes, and some may even result in trade-offs, e.g., tree plantations that produce carbon sequestration benefits but do not provide habitat to support high biodiversity (Onaindia et al. 2013). It is therefore essential to develop a more detailed and nuanced understanding of the intersectionality between climate action and biodiversity imperatives to develop an integrated framework for in-depth analysis of integrated planning and policy opportunities and challenges. Newell et al. (2018) demonstrated that this integration can be done by "mapping" relationships between co-benefits and trade-offs and identifying strategies that support multiple sustainability objectives (i.e., co-benefits) and strategies that support some objectives while conflicting with others (i.e., tradeoffs). Previous research has identified these types of relationships between climate and biodiversity strategies, presenting examples such as maintaining green space that enhances biodiversity and also contributes to climate mitigation and adaptation through carbon sequestration and flood protection (Raymond et al. 2017, Spencer et al. 2017). Multiple literature reviews have shown that co-benefit relationships between climate action and biodiversity strategies are varied and numerous (e.g., Ürge-Vorsatz et al. 2014, Mayrhofer and Gupta 2016, Karlsson et al. 2020, Sharifi 2021). However, to our knowledge, no studies to date have synthesized this research to create a climate-biodiversity framework for analyzing a particular issue to elucidate the considerations and needs for integrated approaches.

Here, we aim to enhance knowledge in integrated planning and policy by developing and applying a framework for examining sustainability issues and challenges in the context of climate action and biodiversity conservation. The sustainability challenge we selected is the development of wildlife crossings to enhance landscape connectivity, and we chose it for multiple reasons. Firstly, practices in wildlife crossing planning in North America are nascent and comprise uncoordinated and piecemeal strategies (Lister et al. 2015). Secondly, effectively implementing wildlife crossings can result in clear co-benefits such as protecting wildlife and ecological health while also contributing to human safety by reducing traffic accidents (Clevenger and Waltho 2005, Beckmann et al. 2010, Clevenger and Barrueto 2014). Thirdly, wildlife species are expected to shift habitats and migration patterns to adapt to changing environments (Heller and Zavaleta 2009, Mawdsley et al. 2009); thus, integrated long-term planning and coordinated strategic policy interventions are even more important to minimize the ecological, social, and economic impacts of habitat fragmentation (Lister et al. 2015).
Our study was conducted in two stages: (1) developing an analytical framework for examining issues in the context of climate action and biodiversity conservation co-benefits and trade-offs, and (2) applying the framework to wildlife crossing challenges to elucidate opportunities and challenges for integrated planning and policy. The first stage involved a review of select literature on climate action and biodiversity conservation co-benefits and trade-offs, particularly focusing on literature reviews, and this work informed the development of an analytical framework. The second stage involved applying the framework to wildlife crossing planning and policy, using Canada (with a focus on Ontario) as a case study, and analyzing data collected through interviews with government, nongovernmental organization (NGO), and private-sector stakeholders. These data were collected as part of a larger research project entitled "Safe Passage" (https://ecologicaldesignlab.ca/project/safe-passage-towardsan-integrated-planning-approach-to-landscape-connectivity/), which aims to improve sustainable planning, design, and implementation of crossing infrastructure and landscape connectivity in North America. This study informs and serves as a basis for other research currently being conducted by the authors, namely a research project on integrated community sustainability planning entitled "The Climate-BiodiversityHealth (CBH) Nexus" (https://www.ufv.ca/food-agricultureinstitute/the-research/integrated-planning/integrated-food-systemsplanning/).

\section{METHODS}

\section{Integrated climate-biodiversity framework}

A review of select literature informed the development of the analytical framework, referred to here as the integrated climatebiodiversity framework (ICBF). It is important to recognize that the intent of this work was not to conduct an exhaustive review of studies of co-benefits and trade-offs because such reviews have already been conducted (e.g., Ürge-Vorsatz et al. 2014, Mayrhofer and Gupta 2016, Karlsson et al. 2020, Sharifi 2021). Instead, our study leverages the work done in these comprehensive reviews to develop ICBF. As noted by Choi et al. (2021), the numbers of studies that focus on a particular type of strategy-co-benefit relationship (e.g., parks, carbon sequestration, and habitat) do not represent the strength or validity of the relationship; rather, they simply indicate where research attention has been focused. Thus, we deemed it appropriate to focus on literature reviews to develop ICBF instead of doing another comprehensive review.

Many of the individual literature reviews we read would be sufficient for developing an analytical framework for examining co-benefits, and some reviews have made efforts to map complex relationships between strategies or actions and co-benefits, for example, Karlsson et al.'s (2020) review of climate policy cobenefits. However, we examine multiple reviews for two reasons. Firstly, most of the reviews focus on co-benefits using either a climate change or a biodiversity lens (with more focusing on climate change), whereas the aim of ICBF is to synthesize work done on both climate action and biodiversity conservation cobenefits. Secondly, a number of reviews center on a particular context or field of study, for example, Bustamante et al.'s (2014) co-benefits review of the agriculture, forestry, and other land use sectors. Therefore, building ICBF based on multiple reviews is valuable in that it ensures the framework captures co-benefits seen in a variety of planning and policy contexts. 
To create ICBF, we conducted a search using Google Scholar that targeted reviews. We used the search terms "climate change", "biodiversity", "co-benefits", "trade-offs", and "review". We then short-listed reviews that referred to both climate action and biodiversity strategies (and outcomes). The initial selection of reviews comprised 22 papers, which was reduced to 16 after removing papers that focused on outcomes with only vague discussions of strategies and policies. The selection was enriched with five more papers found through the search; these were not reviews, but they were deemed worthwhile inclusions because they used survey or systems mapping approaches to identify multiple climate-biodiversity co-benefit or trade-off relationships (e.g., Bain et al. 2016, Newell et al. 2018) or because they clearly focused on the intersection between climate and biodiversity in the cobenefits context (e.g., Chan et al. 2011, Onaindia et al. 2013, Sollmann et al. 2017). The resulting selection comprised 21 papers (Table 1).

Table 1. List of references used to develop the integrated climatebiodiversity framework.

\begin{tabular}{lll}
\hline \hline Source & Research method & References \\
\hline Bain et al. 2016 & Survey & 35 \\
Bustamante et al. 2014 & Review & 123 \\
Chan et al. 2011 & Models & 67 \\
Choi et al. 2021 & Review & 118 \\
Colléony and Shwartz 2019 & Review & 113 \\
Green and Minchin 2012 & Review (short article) & 12 \\
Houghton and Castillo- & Review & 124 \\
Salgado 2017 & & \\
Karlsson et al. 2020 & Review & 243 \\
Mayrhofer and Gupta 2016 & Review & 72 \\
Milner et al. 2012 & Review & 12 \\
Newell et al. 2018 & Models (systems & 64 \\
& maps) & \\
Onaindia et al. 2013 & Models & 51 \\
Phelps et al. 2012 & Review & 67 \\
Raymond et al. 2017 & Review & 158 \\
Reynolds et al. 2020 & Review & 43 \\
Robinson and Breed 2019 & Review & 80 \\
Schwanitz et al. 2015 & Models & 29 \\
Sharifi 2021 & Review & 72 \\
Sollmann et al. 2017 & Models & 81 \\
Spencer et al. 2017 & Review (case studies) & 71 \\
Ürge-Vorsatz et al. 2014 & Review & 154 \\
& & \\
\hline
\end{tabular}

The papers selected to develop ICBF were imported into Mendeley (v.1.19.4; London, UK) reference management software. Climate-biodiversity co-benefits and trade-offs were identified in the papers using Mendeley's annotation (i.e., commenting) feature following a thematic coding approach (Seidel and Kelle 1995, Gibbs 2007). Codes were categorized as either "strategies" or "outcomes". As per Newell et al. (2018), this procedure allowed clear identification of relationships between strategies and various benefits and trade-offs. Coding employed an inductive approach (Thomas 2006), which involved both applying and revising a coding framework as the papers were reviewed. Such an approach involved open coding, meaning that themes and topics were identified in the papers as they were reviewed. An annotation could contain multiple codes to identify areas where strategies and their respective outcomes were discussed together in a paper. The papers, annotations, and codes
Table 2. Biodiversity and climate change strategies, outcomes, and relevant literature.

\begin{tabular}{|c|c|c|}
\hline Type & Strategy or outcome & Source $^{\dagger}$ \\
\hline Strategy & Biochar & 2,8 \\
\hline Strategy & Biofuel & $2,17,21$ \\
\hline Strategy & Biomass & $2,8,17$ \\
\hline Strategy & Brownfield redevelopment & $7,11,14,18$ \\
\hline Strategy & Densification, mixed use & $5,7,11$ \\
\hline Strategy & Diversify and rotate crops & $2,5,15$ \\
\hline Strategy & Drought-resilient species & $4,15,18$ \\
\hline Strategy & Energy conservation & $1,2,4,8,9,10,21$ \\
\hline Strategy & $\begin{array}{l}\text { Integrated forest and } \\
\text { agricultural land }\end{array}$ & 2 \\
\hline Strategy & Permeable and green surfaces & $4,5,7,11,14,15,20$ \\
\hline Strategy & $\begin{array}{l}\text { Protect and maintain forest } \\
\text { land }\end{array}$ & $\begin{array}{l}3,4,5,8,9,11,12,13,17,18,19, \\
21\end{array}$ \\
\hline Strategy & $\begin{array}{l}\text { Protect and maintain non- } \\
\text { forest natural spaces }\end{array}$ & $7,13,19,20,18,21$ \\
\hline Strategy & Renewable energy & $1,2,4,8,9,10,11,17,21$ \\
\hline Strategy & Trails and greenways & 11,15 \\
\hline Strategy & Urban farms & $16,18,20$ \\
\hline Strategy & Urban vegetation & $4,5,15,18$ \\
\hline Strategy & $\begin{array}{l}\text { Vegetation on slopes and } \\
\text { banks }\end{array}$ & 3,12 \\
\hline Strategy & Wildfire management & $6,11,20$ \\
\hline Strategy & Wind turbines & 21 \\
\hline Outcome & Air quality & $1,2,4,5,8,9,10,11,17,21$ \\
\hline Outcome & $\begin{array}{l}\text { Carbon sequestration and } \\
\text { storage }\end{array}$ & $\begin{array}{l}3,4,5,6,7,8,11,12,14,15,17 \\
18,19,20\end{array}$ \\
\hline Outcome & Flood protection & $3,4,7,11,14,15,18,20,21$ \\
\hline Outcome & $\begin{array}{l}\text { Improved farm productivity } \\
\text { and longevity }\end{array}$ & $2,15,20,21$ \\
\hline Outcome & Insectivores & $5,15,21$ \\
\hline Outcome & Land efficiency & $2,5,7,11,18,20$ \\
\hline Outcome & Local temperature regulation & $4,5,7,10,11,14,15,18,20,21$ \\
\hline Outcome & Maintenance requirements & 4,15 \\
\hline Outcome & Pest management & 15 \\
\hline Outcome & Pollination & $5,11,15$ \\
\hline Outcome & Reduced erosion & $2,3,4,7,8,14,15,20$ \\
\hline Outcome & Reduced imports & $8,9,18,21$ \\
\hline Outcome & Reduced fertilizers & $2,5,4$ \\
\hline Outcome & $\begin{array}{l}\text { Reduced run-off, stormwater } \\
\text { management }\end{array}$ & $4,5,7,11,14,15,18$ \\
\hline Outcome & Reduced traffic & $8,10,11,18,21$ \\
\hline Outcome & Space for public parks & $1,4,7,11,15,16$ \\
\hline Outcome & Tree plantation & $2,12,13$ \\
\hline Outcome & Urban noise reduction & $4,5,15,21$ \\
\hline Outcome & Walkability & $7,8,11,15,16,18$ \\
\hline Outcome & Water conservation & $4,7,15,18,20$ \\
\hline Outcome & Water quality & $2,4,7,3,8,9,11,18,21$ \\
\hline Outcome & $\begin{array}{l}\text { Water retention, flow } \\
\text { regulation }\end{array}$ & $2,4,7,8,11,12,15,18$ \\
\hline
\end{tabular}

${ }^{\dagger} 1$ = Bain et al. (2016), 2 = Bustamante et al. (2014), $3=$ Chan et al. (2011), $4=$ Choi et al. (2021), $5=$ Colléony and Shwartz (2019), $6=$ Green and Minchin (2012), 7 = Houghton and Castillo-Salgado (2017), $8=$ Karlsson et al. (2020), $9=$ Mayrhofer and Gupta (2016), $10=$ Milner et al. (2012), $11=$ Newell et al. (2018), 12 = Onaindia et al. (2013), 13 = Phelps et al. (2012), $14=$ Raymond et al. (2017), $15=$ Reynolds et al. (2020), $16=$ Robinson and Breed (2019), $17=$ Schwanitz et al. (2015), $18=$ Sharifi (2021), $19=$ Sollmann et al. (2017), $20=$ Spencer et al. (2017), 21 = Ürge-Vorsatz et al. (2014).

were reviewed a second time to refine and create a more concise coding framework by aggregating like themes or topics within a common code (e.g., bioswales and green roofs were both included within a "permeable and green surfaces" code). The process resulted in a total of 40 codes applied to the articles (Table 2).

After applying codes, coded data and relationships were examined to identify broader themes (Saldaña 2009) that represented major 
climate-biodiversity planning and policy areas. Annotations in Mendeley were then color-coded by theme, meaning that the color of the annotations and comments was selected based on the planning and policy area with which they were associated. The annotations were then exported and used to inform a "relationship mapping" process using techniques similar to those developed by Newell et al. $(2018,2020 b)$ to identify and visualize connections among themes, strategies, and outcomes. Such a mapping process involved examining the color and content of the annotations to identify relationships between planning or policy areas (i.e., annotation color) and strategies (i.e., annotation content) and relationships between strategies and outcomes (i.e., annotation content and codes). Source material was consulted when the nature of relationships between and among strategies and outcomes were unclear based on the exported material.

The analysis of relationships was captured in an Excel spreadsheet as a list of nodes and edges. The list was subsequently converted to comma-separated-variable format and imported into $\mathrm{yEd}$ Graph Editor (v. 3.17.2; yWorks, Tübingen, Germany) to draw and visualize relationships using node and edge elements. This process produced a systems map that gives a holistic picture of complex connections among strategies, benefits, and challenges in integrated climate-biodiversity planning and policy.

\section{Applying the integrated climate-biodiversity framework}

One of the activities of the Safe Passage project was a series of semi-structured interviews with local $(N=5)$, regional $(N=2)$, provincial $(N=11)$, and federal $(N=3)$ government personnel, and $\operatorname{NGO}(N=3)$ and private sector $(N=4)$ practitioners working in the field of wildlife crossing and landscape connectivity in Canada. Safe Passage focused specifically on the wildlife crossing components of landscape connectivity; thus, the government participants were associated with agencies and departments involved in transportation infrastructure, parks and ecological conservation, and local planning, and the NGO and private sector participants worked in the fields of conservation and landscape connectivity.

The interview protocol was developed and deployed in 2018, and it was approved by Ryerson University's Research Ethics Board. Interview questions were designed to interrogate three major areas: policies and plans, implementation of plans and strategies, and data used for informing and evaluating wildlife crossing and (broadly) landscape connectivity efforts. The interview protocol was not specifically designed for our study; however, the data set is related to wildlife crossings and was deemed appropriate for using ICBF to investigate challenges and opportunities in maintaining or enhancing landscape connectivity. Specific interview questions that supported our study were those that asked about current wildlife crossing and landscape connectivity plans and policies, barriers to implementing connectivity strategies, wildlife crossing infrastructure design and implementation, and agencies involved in landscape connectivity efforts.

The list of potential interviewees was developed by the third author as part of Safe Passage, and additional participants were identified through expert peer referrals (i.e., snowball sampling). Altogether, 28 people were interviewed. The majority of participants were based in Ontario $(N=15)$ and Alberta $(N=7)$, which are leading provinces in terms of wildlife crossings; however, interviewees also included people working in British Columbia $(N=2)$, Manitoba $(N=1)$, and Nova Scotia $(N=3)$. Interviews were conducted by phone, and each interview lasted approximately one hour. Most interviews involved one participant, but some involved two or three participants (i.e., 28 participants were interviewed in 23 sessions).

Interview data were analyzed using ICBF, which provided a lens for examining landscape connectivity issues within the constellation of climate action and biodiversity conservation relationships. Specifically, the ICBF themes (i.e., major planning and policy areas) were used as a coding framework that was applied to the data using RQDA (v. 0.3-1; Ronggui 2016). Coded data were then examined within the context of the ICBF systems map to see where different aspects of landscape connectivity issues and approaches align or conflict with climate change and biodiversity strategies and objectives. This insight revealed challenges and opportunities for integrated approaches to wildlife crossing planning and landscape connectivity policy.

\section{RESULTS}

\section{Integrated climate-biodiversity framework relationships and systems map}

The systems map of co-benefit and trade-off relationships in the analytical framework is anchored by biodiversity and climate action objectives (Fig. 1). Biodiversity objectives include habitat protection and preservation (e.g., allocating space for habitat, protecting air and water quality) and wildlife health and wellbeing (e.g., reducing incidents of wildlife morbidity and mortality, promoting pollination and propagation). Climate action objectives include mitigation (i.e., efforts to reduce greenhouse gas emissions) and adaptation (i.e., efforts to increase resilience to climate change impacts). In both cases, objectives are mutually supportive and interdependent, but they are disaggregated in the map to convey more clearly how different strategies relate to climate action or biodiversity conservation.

The majority of relationships in the ICBF systems map represent co-benefits. This result could be due to the nature and focus of the literature we reviewed in that much of the research in this area focuses more on co-benefits than adverse effects. However, some challenges and trade-offs were identified. For example, replacing fossil fuels with biofuel energy was identified through the review as a potential climate action strategy that can also conflict with agriculture because of land needs for bioenergy crops (Bustamante et al. 2014), potentially promoting more land conversion and habitat destruction.

Six themes were identified through the literature review and are featured in ICBF as major planning and policy areas: green space, transportation, green infrastructure, food and agriculture, energy, and land management. Green space (Fig. 2) refers to natural lands that remain as undeveloped habitat (Onaindia et al. 2013) or are designated or developed as public parks (e.g., Robinson and Breed 2019). ICBF differentiates between green space that is with and without forest cover because both provide important wildlife habitat but can differ in their relationships to other strategies. For example, agroforestry strategies involve the integration of forest and agriculture (Bustamante et al. 2014). Choi et al. (2021) note that much of the co-benefits literature focuses on protecting or enhancing forest land and trees as carbon sequestration strategies, 
Fig. 1. Systems map of the co-benefit and trade-off relationships in the integrated climate-biodiversity framework. Grey rectangular nodes $=$ climate change and biodiversity objectives, brown hexagonal nodes $=$ major planning and policy areas, blue octagonal nodes $=$ strategies, and orange elliptical nodes = outcomes (benefits, trade-offs). Node types are distinctive in both shape and colour to allow for differentiation when printed in greyscale. Solid green edges $=$ positive relationships, red dashed lines = negative relationships. Edge lengths do not represent any aspect of the nature of the relationships and differ solely for layout purposes.

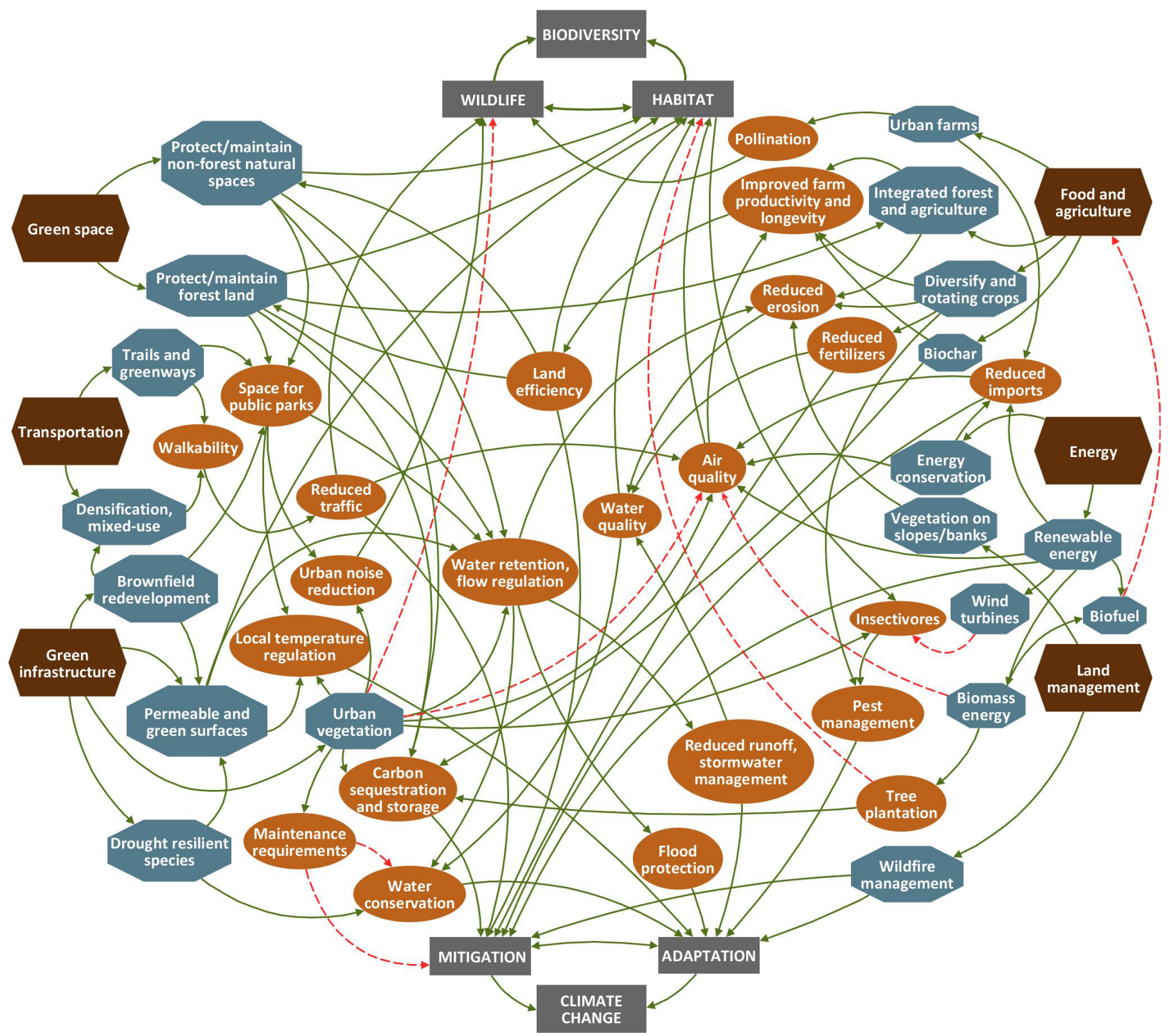

but we observed the recognition of the carbon storage value of nonforest habitats such as mangroves (Ürge-Vorsatz et al. 2014) and grasslands (Onaindia et al. 2013) in our literature review.

The transportation theme (Fig. 3) includes strategies for reducing vehicle traffic and encouraging active transportation, e.g., enhanced pedestrian networks, mixed-use development, and increased community walkability (Newell et al. 2018, Sharifi 2021). These strategies can decrease vehicle-related greenhouse gas emissions while also producing biodiversity co-benefits associated with better air quality (Bain et al. 2016) and fewer wildlife-vehicle collisions (Ürge-Vorsatz et al. 2014). This planning and policy area also includes strategies that integrate parks and greenways in active transportation networks (i.e., pedestrian, bicycles), which can lead to traffic reduction while providing wildlife habitat (Newell et al. 2018).

The green infrastructure theme (Fig. 4) focuses on landscape and urban purpose-built and adaptive design features that incorporate vegetation and permeable surfaces such as urban trees, bioswales, 
Fig. 2. Green space relationships and pathways in the integrated climate-biodiversity framework. Grey rectangular nodes $=$ climate change and biodiversity objectives, brown hexagonal nodes $=$ major planning and policy areas, blue octagonal nodes $=$ strategies, and orange elliptical nodes = outcomes (benefits, trade-offs). Node types are distinctive in both shape and colour to allow for differentiation when printed in greyscale. Solid green edges = positive relationships, red dashed lines = negative relationships. Edge lengths do not represent any aspect of the nature of the relationships and differ solely for layout purposes.

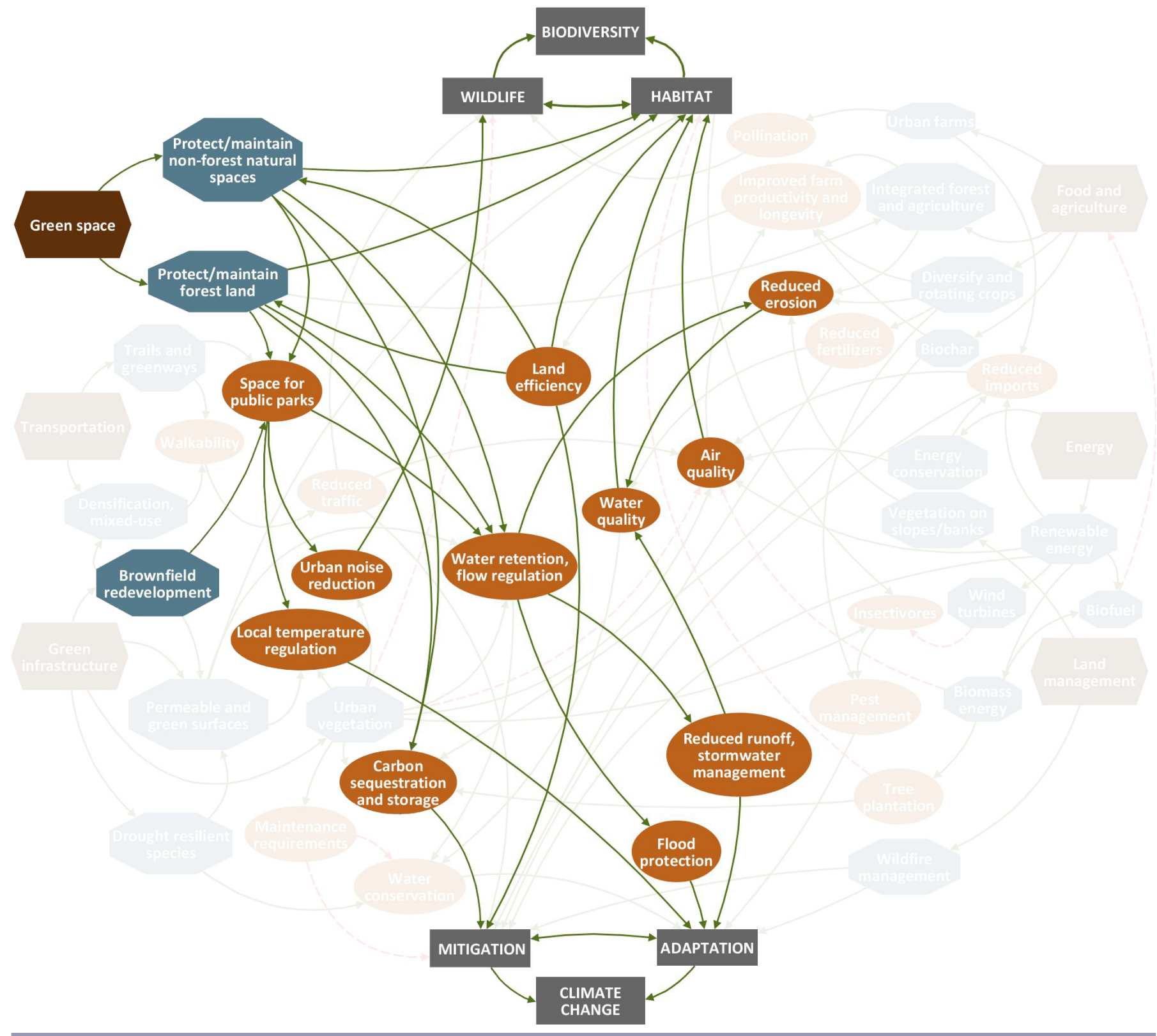

green roofs, living walls, and rain gardens. This theme differs from the green space theme because it refers to purpose-built (usually urban) green features and elements that may be too small to provide significant wildlife habitat but perform valuable ecological functions such as reducing erosion and run-off into freshwater systems (Raymond et al. 2017). Green infrastructure serves important climate adaptation functions such as stormwater management through holding, infiltration, and filtering run-off, and localized temperature regulation though urban shading and cooling (Newell et al. 2018). In addition, although not sizeable habitat, urban trees can support local insectivore populations such as birds and bats (Colléony and Shwartz 2019). Some trade-offs were identified with green infrastructure, particularly with urban vegetation. Urban trees often require significantly more soil, energy, and water compared to vegetation found within natural environments (Reynolds et al. 2020). In addition, relationships with air quality are mixed (Colléony and Shwartz 2019), with some research identifying impacts from urban trees such as pollen and 
Fig. 3. Transportation relationships and pathways in the integrated climate-biodiversity framework. Grey rectangular nodes $=$ climate change and biodiversity objectives, brown hexagonal nodes $=$ major planning and policy areas, blue octagonal nodes $=$ strategies, and orange elliptical nodes = outcomes (benefits, trade-offs). Node types are distinctive in both shape and colour to allow for differentiation when printed in greyscale. Solid green edges = positive relationships, red dashed lines = negative relationships. Edge lengths do not represent any aspect of the nature of the relationships and differ solely for layout purposes.

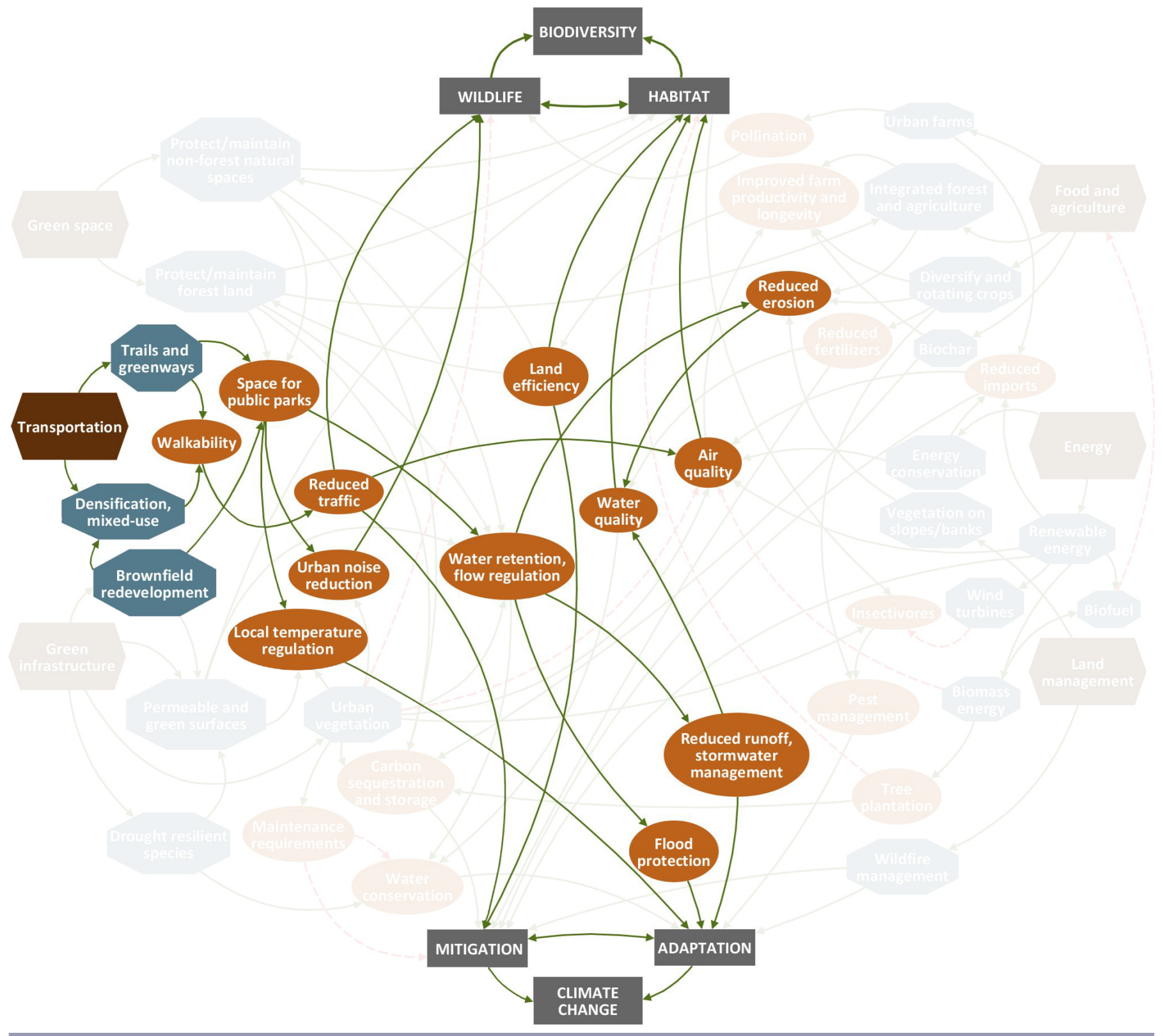

volatile organic compound production and (when densely planted) air quality impacts from reducing wind flow and ventilation (Choi et al. 2021). Furthermore, urban vegetation can contribute to biodiversity issues when it consists of non-native species and results in the spread of invasive plants (Colléony and Shwartz 2019, Choi et al. 2021).

The food and agriculture theme (Fig. 5) centers on sustainable food production. It includes farming approaches that involve the reduced use of nitrogen fertilizers to decrease nitrous oxide (i.e., greenhouse gas) emissions and freshwater eutrophication (Bustamante et al. 2014). It also includes techniques for enhancing soil carbon (Karlsson et al. 2020) and improving farm productivity to minimize land conversion for agricultural purposes (Spencer et al. 2017). An agricultural strategy with climate-biodiversity cobenefits is the integration (or retention) of forest on agricultural land (i.e., agroforestry). This strategy can improve farm productivity by protecting land from water and wind erosion (Bustamante et al. 2014) while contributing to carbon sequestration 
Fig. 4. Green infrastructure relationships and pathways in the integrated climate-biodiversity framework. Grey rectangular nodes $=$ climate change and biodiversity objectives, brown hexagonal nodes $=$ major planning and policy areas, blue octagonal nodes $=$ strategies, and orange elliptical nodes = outcomes (benefits, trade-offs). Node types are distinctive in both shape and colour to allow for differentiation when printed in greyscale. Solid green edges $=$ positive relationships, red dashed lines = negative relationships. Edge lengths do not represent any aspect of the nature of the relationships and differ solely for layout purposes.

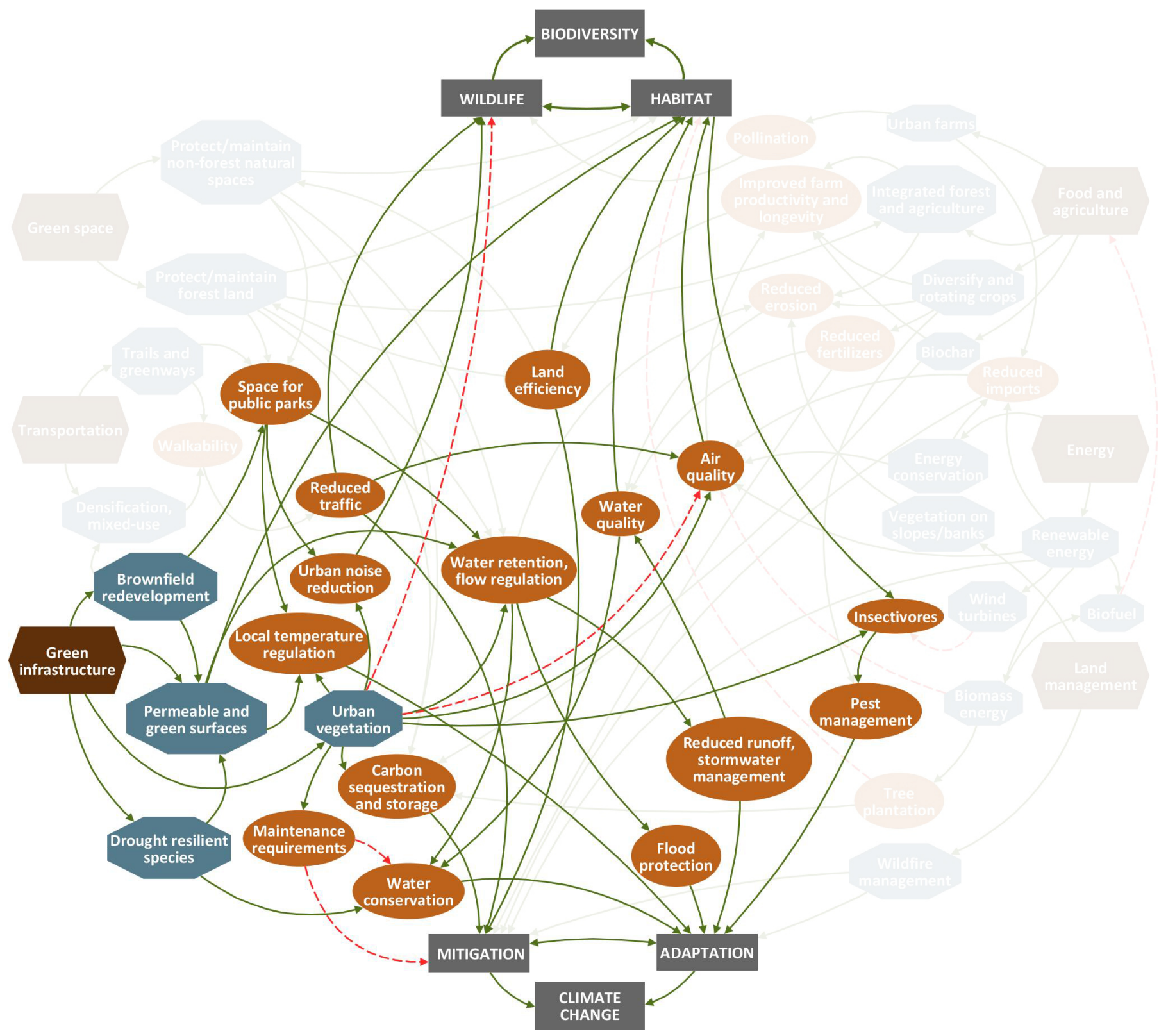

and wildlife habitat. The food and agriculture theme also includes local and urban agriculture, which can support climate action and biodiversity conservation or enhancement by reducing food imports (Newell et al. 2018) and contributing to plant-pollinator relationships (Reynolds et al. 2020).

The energy theme (Fig. 6) focuses on reductions in energy consumption and a transition to renewable sources, with cobenefits relating to decreased greenhouse gas emissions and increased air quality (Karlsson et al. 2020). A number of trade-offs are seen with this theme, depending on the types of energy sources considered to be viable renewable alternatives. For example, transition to biomass energy could reduce greenhouse gas emissions (Ürge-Vorsatz et al. 2014) and open opportunities for sequestering carbon in bioenergy plantations (Onaindia et al. 2013), but this strategy also conflicts with biodiversity objectives due to air pollutants produced by biomass combustion (Schwanitz et al. 2015) and replacement of high-quality habitat with monocultures (Onaindia et al. 2013, Bustamante et al. 2014). Other biodiversity 
Fig. 5. Food and agriculture relationships and pathways in the integrated climate-biodiversity framework. Grey rectangular nodes $=$ climate change and biodiversity objectives, brown hexagonal nodes $=$ major planning and policy areas, blue octagonal nodes $=$ strategies, and orange elliptical nodes = outcomes (benefits, trade-offs). Node types are distinctive in both shape and colour to allow for differentiation when printed in greyscale. Solid green edges $=$ positive relationships, red dashed lines = negative relationships. Edge lengths do not represent any aspect of the nature of the relationships and differ solely for layout purposes.

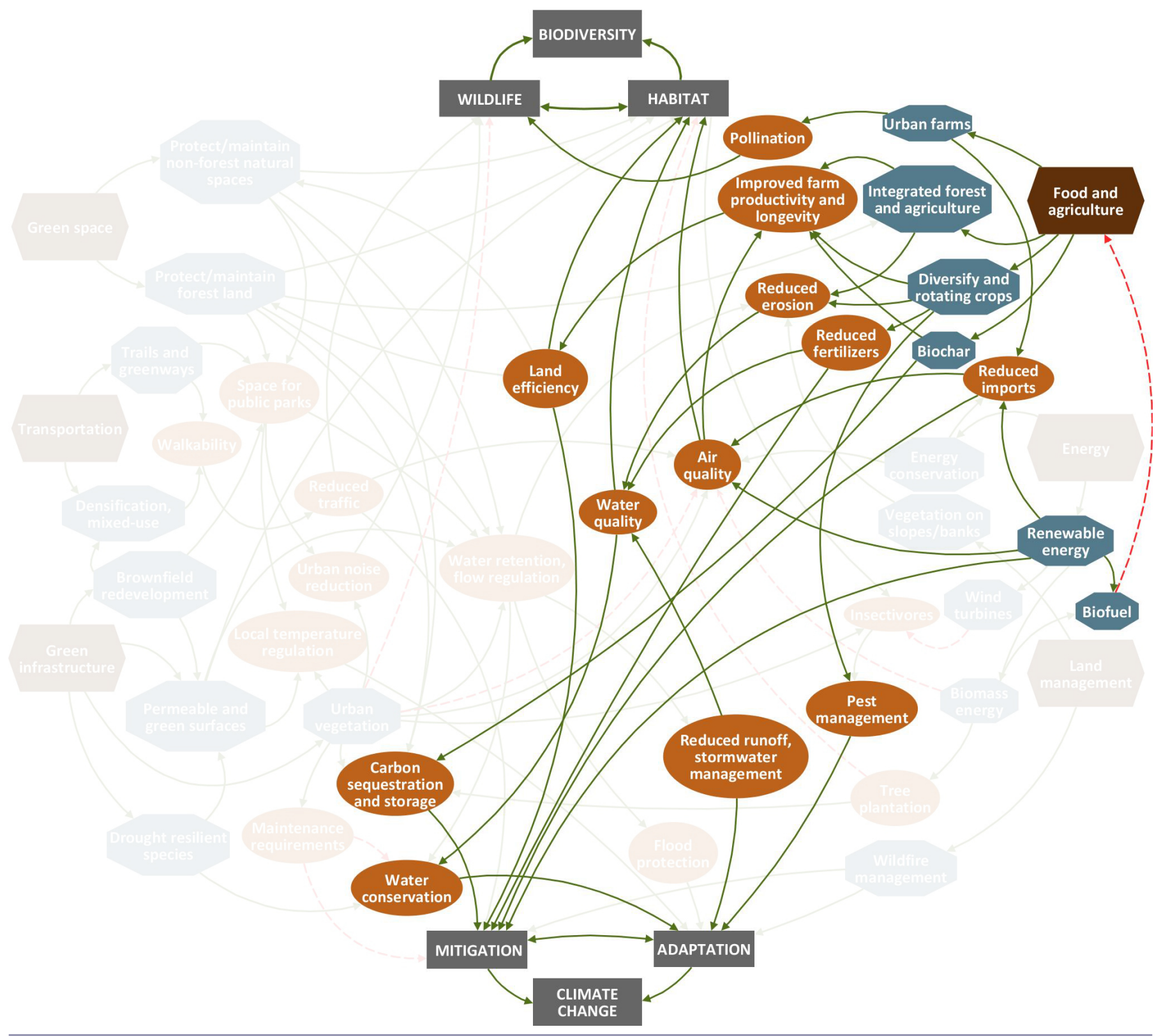

trade-offs include those observed with wind energy and its effects on bird and bat species (Saidur et al. 2011). These effects are relatively minor compared to other threats such as vehicle collisions (Ürge-Vorsatz et al. 2014); regardless, it was deemed worthwhile to feature the trade-off in ICBF because it represents a potential conflict and also relates to other aspects of the systems map, particularly the pest management functions of insectivores (Colléony and Shwartz 2019, Reynolds et al. 2020).

The land management theme (Fig. 7) captures co-benefits related to land practices such as wildfire management and stabilization of slopes and riparian areas. Effective wildfire management, which includes controlled burning, is inherently integrative of biodiversity and climate objectives because it protects habitat from uncontrolled wildfire spread and destruction while limiting the release of stored carbon into the atmosphere (Green and Minchin 2012). Slope or riparian stabilization refers to the maintenance of vegetation and stability of graded land to reduce erosion and sediment flow into water systems and aquatic habitats (Chan et al. 2011), which is particularly important for landscape resilience during highprecipitation events (i.e., climate adaptation). 
Fig. 6. Energy relationships and pathways in the integrated climate-biodiversity framework. Grey rectangular nodes $=$ climate change and biodiversity objectives, brown hexagonal nodes $=$ major planning and policy areas, blue octagonal nodes $=$ strategies, and orange elliptical nodes = outcomes (benefits, trade-offs). Node types are distinctive in both shape and colour to allow for differentiation when printed in greyscale. Solid green edges = positive relationships, red dashed lines = negative relationships. Edge lengths do not represent any aspect of the nature of the relationships and differ solely for layout purposes.

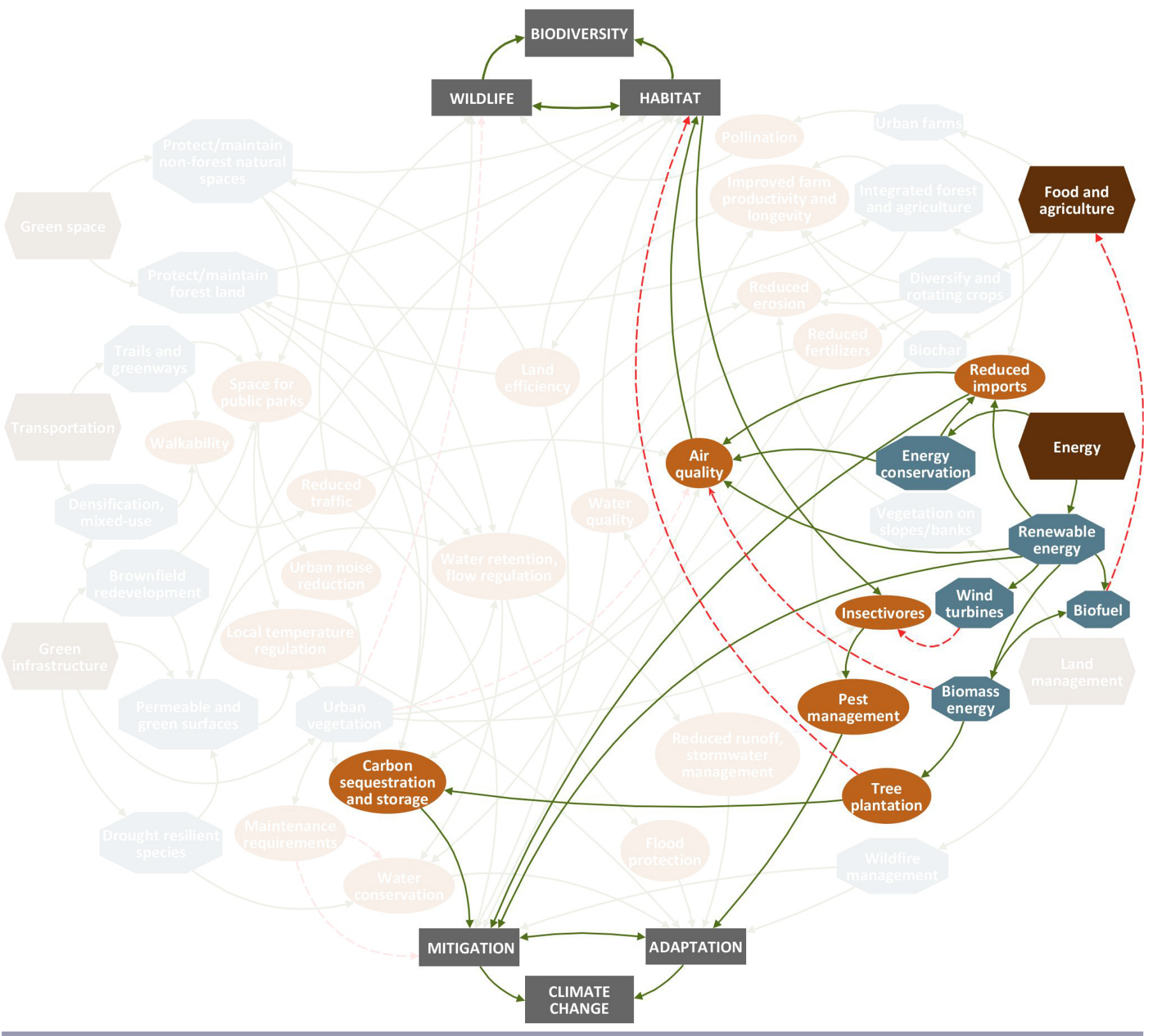

\section{Application of the integrated climate-biodiversity framework to wildlife crossings and landscape connectivity}

The application of ICBF to the interview data produced insights about challenges and opportunities for integrated landscape connectivity planning and policy. We discuss the results of this analysis in reference to the six themes featured in ICBF (i.e., the six major planning and policy areas). We make reference to the various co-benefit and trade-off relationships within the ICBF systems map (Fig. 1). We use illustrative quotations, but participants are identified using numbers to maintain anonymity and to respect research ethics standards and protocols. Because of the semistructured interview methods employed, there is no way to ascertain the level of agreement for each of the points (i.e., how many interviewees would have agreed with a comment, if it was presented to them). This research follows the methods of other qualitative studies that target expert stakeholders for interviews (e.g., van der Hel 2016, Wang et al. 2018) to gain information from select participants with sufficient experience and knowledge to provide 
Fig. 7. Land management relationships and pathways in the integrated climate-biodiversity framework. Grey rectangular nodes $=$ climate change and biodiversity objectives, brown hexagonal nodes $=$ major planning and policy areas, blue octagonal nodes $=$ strategies, and orange elliptical nodes = outcomes (benefits, trade-offs). Node types are distinctive in both shape and colour to allow for differentiation when printed in greyscale. Solid green edges $=$ positive relationships, red dashed lines = negative relationships. Edge lengths do not represent any aspect of the nature of the relationships and differ solely for layout purposes.

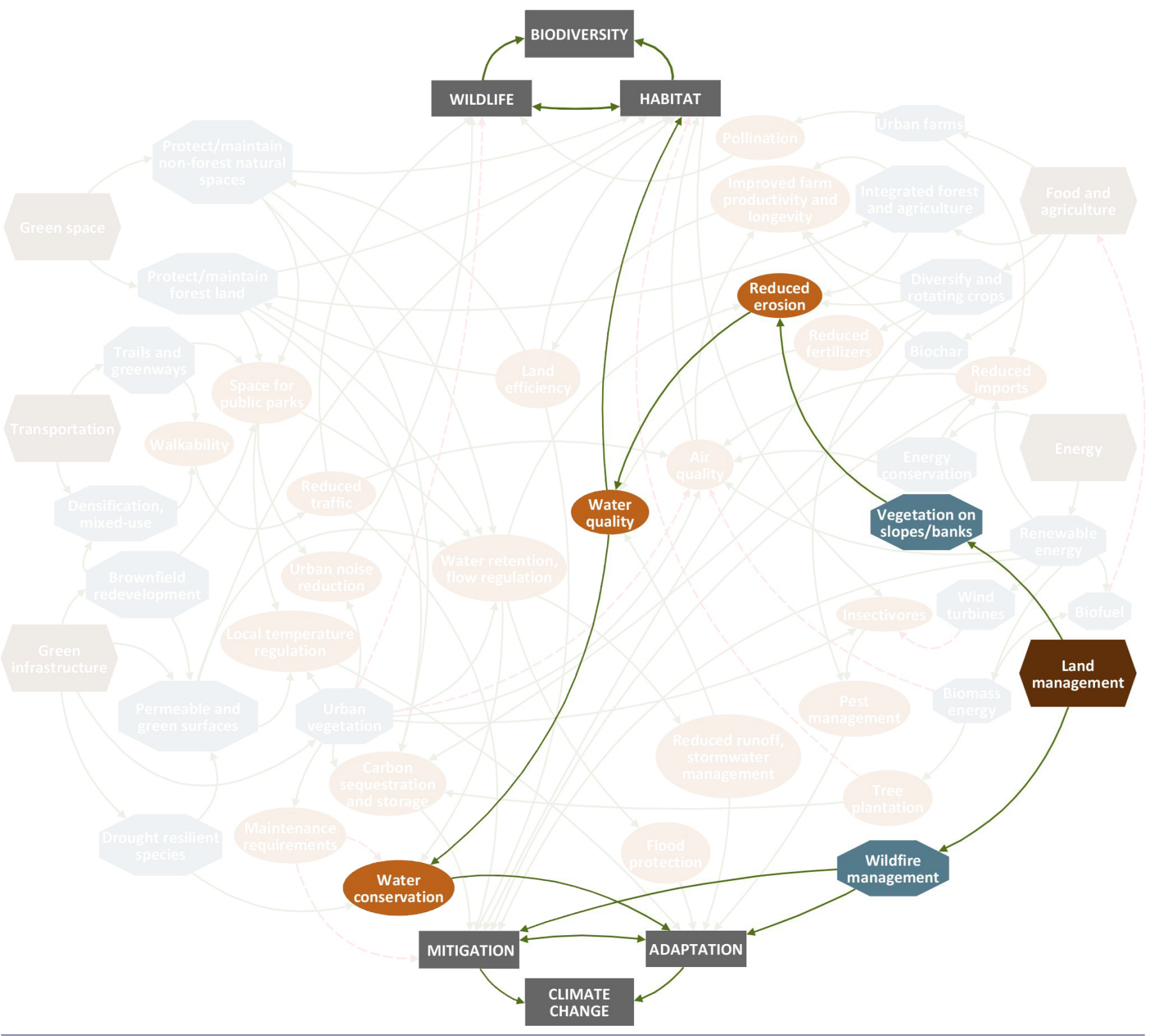

useful and accurate insights about a topic or issue, and in this way, each quotation represents an insight from a reliable source. Future research could test findings from an application of ICBF using focus groups to determine whether there is consensus about different insights and recommendations for integrated approaches in various planning and policy areas.

\section{Green space}

Green space was the most frequently coded theme in the data, which is perhaps unsurprising because of the clear linkages between this planning and policy area and the preservation and restoration of ecological corridors for landscape connectivity. We found evidence of some climate-biodiversity integration in wildlife crossing and landscape connectivity planning occurring in Canada, specifically at the local level, where progressive municipal governments have identified linkages between ecological connectivity and climate adaptation objectives (e.g., City of Edmonton 2016). However, further opportunities for effective integrated planning exist, particularly in recognizing both the importance and nuanced 
functions of diverse green space. For example, there was little evidence of planning that identifies the nuanced land or ecosystem potential to support climate mitigation (e.g., carbon sequestration or storage), adaptation (e.g., temperature regulation, water flow control), and wildlife habitat for various local species (e.g., habitat types). One participant noted that traditional biodiversity conservation was about simply ensuring that there is "green stuff in the landscape", and although progress has been made, further work is needed in better recognizing the quality and ecosystem services of different habitat types and structures.

We've come a long way from thinking that habitat and
biodiversity is [about], 'okay, put some green stuff in the
landscape and that should be fine', to now talking about
the functions within those green spaces, and also talking
about what happens when we fragment those green
spaces. (Participant 15)

Opportunities for integrated approaches were also found beyond local contexts, some of which have promise for overcoming barriers to implementing effective regional wildlife crossing and landscape connectivity strategies, particularly those related to jurisdictional boundaries. Groups such as national parks agencies have mandates to protect habitat and restore connectivity in expansive areas; however, even in these cases, there are still challenges in extending these efforts beyond park limits. Interviewees explained that collaborative initiatives such as "Yellowstone to Yukon" and "Two Countries, One Forest" have been effective for creating partnership networks of NGO and government groups to maintain, protect, enhance, and restore large-scale bioregional connectivity. Expanding the scope of these partnerships to integrate broader sustainability objectives and groups could open valuable opportunities to increase multiple cobenefits, for example, including climate action organizations to leverage funding related to activities such as protecting lands for carbon offsets.

Our analysis revealed that a major challenge for integrated approaches to wildlife crossing planning is the single-species focus that dominates current practices. Interviewees explained that the implementation of landscape connectivity infrastructure is often triggered by the presence of species-at-risk, indicating that connectivity strategies often focus narrowly on local populations of a particular type of animal rather than including broader ecosystems and habitat conservation. Furthermore, it was explained that crossing infrastructure is built to accommodate certain species, with much of the focus being vulnerable reptiles and amphibians or charismatic and iconic large mammals (e.g., lynx, cougar, grizzly bear, elk), and one interviewee noted that more common species such as waterfowl are under-considered and thus poorly represented in connectivity planning. These comments and ICBF illustrate that although protecting vulnerable species is important for conservation priority-setting, ecosystem and climate resilience are best achieved when understanding the broader ecosystem services and values associated with maintaining an extensive green space network (e. g., flood protection, water quality), rather than focusing on specific patches and populations.

\section{Transportation}

The transportation theme exhibited a high incidence of coding (the second highest), which was expected because landscape connectivity priorities and wildlife-vehicle collisions are explicitly featured within the ICBF systems map. The data analysis, however, revealed major gaps between how wildlife crossing and climate action strategies approach transportation issues, providing interesting perspectives on how they can be refocused in integrated planning and policy efforts. Many climate action approaches to transportation center on reducing emissions by decreasing traffic and personal vehicle usage, whereas wildlife crossing decision makers appear to view traffic increases as somewhat of an inevitability that can be mitigated with wildlife crossing structures. The perspective assumed in connectivity planning is (in part) a response to government priorities. As explained by interviewees, these priorities tend to focus on motorist safety rather than wildlife health, with the latter regarded as an added value; therefore, the focus is less about reducing risks to wildlife (i.e., reducing traffic) and more about ensuring that traffic flows without incident. Further supporting this notion are comments by interviewees explaining how wildlife crossings are much more likely to be funded if they are included within earmarked road construction and maintenance projects, indicating that the wildlife objectives are secondary to transportation priorities.

When we look at a highway project where there is major
investment... that involves a significant expansion of the
roadway, we start to look at it and always talk about three
goals that [the parks agency] has: one, of course, is safe
movement of motorists... also the safe movement of
wildlife across the highways... and the third is the efficient
movement of goods. (Participant 26)

The integration of climate action perspectives and objectives into landscape connectivity planning could lead to innovative strategies for reducing traffic burdens while producing a number of co-benefits around biodiversity, health, and quality of life. As seen through ICBF, an integrated approach could focus on developing greenways and highly connected park systems to increase walkability, recreational accessibility, and contiguous public green space, with added public health and well-being benefits, thereby reducing transportation-related emissions and increasing habitat connectivity. Multiple interviewees identified a number of different bridges and pedestrian tunnels that are also adaptively used by wildlife as crossings, indicating that infrastructure intended for human travel can also facilitate wildlife movement and (to some degree) restore landscape connectivity. Integrated approaches to landscape connectivity can take advantage of co-benefit opportunities by strategically designing path and trail systems in ways that incorporate linkages between ecological connectivity and active transportation, such as pedestrian and bicycle bridges that include wildlife underpass accommodations (e.g., Bell et al. 2020). It is important that such strategies also recognize potential trade-offs such as the possibility of human-wildlife conflicts when allowing pedestrian, cyclists, or motorists access to passages that also serve as wildlife crossings.

It's three to five wildlife crossings that do exist. None are specifically wildlife crossings per se. I think a couple of them were built for agriculture, like the movement of cattle, but are called wildlife crossings... ATVS [allterrain vehicles] also use them. (Participant 26) 
Applying ICBF to different geographical contexts can reveal varying challenges and opportunities, which was apparent when analyzing the data through the transportation theme. Opportunities for co-benefits exist when communities attempt to reduce local traffic by developing effective path and trail networks, but that is not necessarily the case when expanding the geographical scope of a planning area. For example, interviewees from national park agencies explained that visitor experience is part of their mandate, and while park and trail infrastructure can contribute to walkability in urban contexts, the same infrastructure in more remote areas ultimately results in road networks (and vehicle traffic) in what would otherwise be undisturbed habitat. Thus, the analysis demonstrated that integrated planning does not have a "one size fits all" approach, and co-benefits and trade-offs for the same strategies can vary depending on the geographical context.

In addition to providing new perspectives for wildlife crossing and landscape connectivity planning, the application of ICBF to connectivity issues elucidated shortcomings associated with certain climate action strategies, particularly strategies that incentivize vehicles not powered by fossil fuels (e.g., Aasness and Odeck 2015). Although these strategies can lead to reductions in greenhouse gas emissions (and better air quality), they do little to reduce traffic and wildlife-vehicle collisions. Perhaps more importantly, these types of strategies can shift attention away from problems around uncontrolled expansion of road networks, which, as interviewees expressed, carries major ecological and carbon footprints.

\section{Green infrastructure}

Much of the coded data within the green infrastructure theme elucidated considerations around the protection of aquatic ecosystems and habitats. A major concern for ecological connectivity is the fragmentation of freshwater ecosystems, which is often addressed by implementing aquatic passages and culverts, mainly through stormwater management planning and mitigation designs. Interviewees explained that these strategies frequently align with drainage and stormwater management priorities, and some integrative thinking in these planning areas currently exists, such as decisions about whether culverts should serve dual purposes or separate infrastructure should be built for wildlife passage and water drainage. However, our analysis found the integration of aquatic connectivity and stormwater management to be relatively narrowly focused, whereas broader integration would incorporate purpose-built green infrastructure and its multitude of co-benefits. Green roofs, bioswales, and other permeable surfaces can serve as strategies for reducing surface run-off and sediment flow into freshwater systems, which decreases stress on aquatic passages and reduces loads on drainage systems and infrastructure. In addition, green infrastructure produces valuable health and comfort co-benefits related to local temperature regulation (which is critical as communities increasingly experience extreme heat events), and planners can continually explore opportunities to implement green infrastructure in integrated climate-biodiversity strategies such as in brownfield and infill development projects (e.g., Rosenzweig et al. 2006, Bowler et al. 2010, Oliveira et al. 2011, Santamouris 2014).
The design of terrestrial wildlife crossing structures provides both a challenge and an opportunity to incorporate green infrastructure into integrated planning. A climate-biodiversity perspective suggests that crossing structures should maximize vegetation cover and have high capacity for water retention, but as noted by interviewees, it is costly to build structures that can support heavy water, soil, and vegetation masses. However, when framing these types of designs as strategies for stormwater management and watershed health, such costs can be incorporated into larger operating budgets. An interviewee working at the municipal level explained that a broader understanding of the ecosystem services provided by various green assets can give a better and more holistic impression of the true cost-benefit associated with preserving or enhancing these assets.

\section{[Ecosystem] services and the valuation of these assets, if we had a true understanding of these assets, and we could put them in a common framework and create a triple bottom line. (Participant 18)}

Another interviewee indicated that a major challenge for ecological connectivity is the developer interest in waterfront spaces; such developments are highly marketable but also place heavy stress on aquatic ecosystems and local biodiversity. This challenge can be partly addressed through integrated approaches to planning such as mandated significant green infrastructure in new developments near water bodies. Such municipal requirements would contribute to freshwater protection while providing co-benefits related to temperature regulation and aesthetics, ultimately making the developments more liveable and appealing. These strategies can also be integrated with green space and transportation planning; for example, land-use bylaws could be designed to provide large buffers beyond 30-m minimums (i.e., Environment Canada 2013) in a manner that designates significant riparian or waterside areas for parks, greenways, and habitat.

\section{Food and agriculture}

The food and agriculture theme was not heavily represented in the data, but our analysis identified agricultural land ownership as a significant challenge for landscape connectivity that could be ameliorated through integrated approaches. Interviewees explained how privately owned land affects efforts to establish and protect ecological corridors because of a lack of control or jurisdiction over how the land is used and managed. In the case of agriculture, land use can include fencing to protect crops from herbivores, which effectively fragments habitats. Interviewees also noted that NGOs can work effectively with landowners to establish easements and restore connectivity, and these opportunities may increase when approaching these partnerships through an integrated perspective. As seen in ICBF, integrating forest and agricultural land can increase farm productivity by protecting soil from water and wind erosion (which is particularly important as climate change brings more extreme weather events). Opportunities exist for farmers, agricultural specialists, and conservation groups to partner and design integrated systems that result in both high agricultural productivity and ecological connectivity.

I see the opportunities with the NGOs like the Habitat Acquisition Trust and the Y2Y [Yellowstone to Yukon] initiative to assemble private properties or get 
environmental easements, and that could guarantee connectivity from one critical habitat to another. (Participant 23)

The research revealed local food production and reduced reliance on imports as another area for integrated planning and policy. Although not explicitly mentioned by interviewees, our analysis indicates that support for and protection of local and small-scale agriculture can facilitate indirect relationships among climate action, biodiversity, and landscape connectivity objectives. Interviewees noted that (in addition to personal vehicles) the transport of goods presents a major threat to ecosystems in terms of wildlife-vehicle collisions; therefore, reducing transport activities can be beneficial for wildlife and landscape connectivity. As seen in ICBF, reduced reliance on imports also can potentially have climate-biodiversity benefits associated with reduced greenhouse gas emissions and air pollutants.

\section{Energy}

Similar to food and agriculture, the energy theme was not heavily represented in the data. Regardless, interesting trade-offs were observed between climate action, biodiversity, and wildlife crossing and landscape connectivity objectives, particularly in terms of wind energy. ICBF captures wildlife concerns related to wind energy and bird and bat mortality (Saidur et al. 2011, ÜrgeVorsatz et al. 2014); however, our analysis suggests that this biodiversity conflict or trade-off may not be the most significant one associated with wind energy development. Instead, the greater challenge could be increased habitat fragmentation because wind energy development can involve developing new roads for servicing wind turbines in otherwise undisturbed habitats.

There is major conflict between Green Energy Act and the Endangered Species Act. They are putting wind farms in endangered species habitats... When you put in wind energy, you need roads access, so it's turning our endangered species roadless areas into development areas. (Participant 1)

Another potential trade-off within the energy theme relates to climate action strategies that involve transitioning from fossil fuels to bioenergy. Although such strategies could potentially reduce greenhouse gas emissions, they ultimately require land to produce biomass and bioenergy crops. As seen in ICBF, bioenergy plantations can consist of monocultures, and thus low-quality habitat, and they can displace agricultural development (i.e., presenting needs for further land conversion), ultimately resulting in trade-offs for biodiversity. Land use for bioenergy cultivation can be regarded in the same way as agricultural land in terms of landscape connectivity objectives, meaning that it fragments highquality habitat and disrupts connectivity. Additionally, indirect co-benefit relationships can be seen with the localization of energy and reduced reliance on requiring mining or harvesting of energy resources. Although this relationship was not explicitly identified by interviewees, it was inferred though comments made about wildlife crossing issues related to both wildlife-vehicle collisions associated with transport of goods and habitat fragmentation from resource extraction operations.

\section{Land management}

Analysis under the land management theme presented similar integration opportunities to those observed with green infrastructure, namely strategies for protecting aquatic ecosystems and habitat. Interviewees discussed how watershed management plans include strategies for erosion control and riparian area stabilization to reduce sediment pollution in freshwater systems. These strategies contribute to landscape connectivity by maintaining the integrity of aquatic passages and riparian corridors. Such strategies have obvious linkages to biodiversity objectives and they support climate adaption by protecting water resources, which is a critical need as communities experience increases in extreme temperatures and drought events.

Our analysis found wildfire management to be nearly absent from the data, with the only related comment being an interviewee broadly discussing how developing roads and transportation infrastructure includes considerations around fire department access. More recently, however, landscape connectivity strategies have come under added scrutiny to consider their potential as wildfire vectors. For example, wildfire is a concern in planning a major wildlife crossing structure for the Agora Canyon in Los Angeles, California, USA (e.g., Riley et al. 2018). Although the Agora Canyon study is outside the scope of our analysis, it demonstrates that ICBF has relevance to wildlife management, and future studies in this area could produce important insights by applying the analytical framework.

\section{DISCUSSION}

Best-and-next practices comprise integrated approaches that recognize linkages among policies, strategies, spatial plans, designs, and broader sustainability objectives (Ling et al. 2009, Shaw et al. 2014, Lister 2015, Dale et al. 2018) because they capture complex interactions in development paths and critical needs to transition toward sustainable development. Examining planning and policy opportunities through an integrated lens is valuable for not only optimizing co-benefits, but also revealing how certain strategies can support one imperative while conflicting with, and potentially undermining, other imperatives. Such insight is critical for employing holistic thinking, and it allows planners and decision makers to recognize potential problems that may arise from placing too much emphasis on one particular type of strategy or approach, the result of which may have unintended consequences elsewhere. An integrated planning approach may allow early and proactive identification of conflicting imperatives, trade-offs, and strategies to minimize or ameliorate negative effects and conflicts. For example, climate action strategies that focus primarily on green fuel sources and green transportation technologies (e.g., biofuels, electric vehicles) can ignore critical landscape connectivity and biodiversity needs related to traffic management and road network expansion. Instead, an integrated approach would incorporate long-term planning and explore ways of enhancing intra- and extra-city transit systems, for example.

A major challenge for wildlife crossing and landscape connectivity planning in North America is that governance is fragmented into different local jurisdictions without any particular agency or organization developing and coordinating cohesive plans and policies (Lister et al. 2015). These are issues related to government silos (Dale 2001), whereby departmental divides prevent effective efforts toward holistic action that extends beyond administrative boundaries. An integrated perspective can help overcome these issues in two ways. Firstly, it can provide insights into which 
departments and agencies need to collaborate to achieve their respective goals and optimize co-benefits. For example, local and regional planning, parks, transportation, conservation, and climate action agencies can coordinate efforts around green infrastructure and riparian corridors to create communities with high ecological connectivity that are also walkable, liveable, and climate resilient (Newell et al. 2018, Robinson and Breed 2019). Secondly, integrated approaches can help to address jurisdictional issues and transboundary challenges. Partnership initiatives that focus on broader bioregional connectivity (e.g., Yellowstone to Yukon; Two Countries, One Forest) can harness opportunities to collaborate with climate action agencies strategically to restore key ecological corridors and protect carbon sequestration (i.e., carbon offsets) assets (Hilty et al. 2019, 2020). Such collaborations can provide opportunities to leverage multiple mandates and funding sources to execute politically viable and financially efficient ways of implementing transboundary climatebiodiversity strategies.

The integrated perspective that we used revealed a number of areas of convergence and co-benefits among climate, biodiversity, and landscape connectivity planning. Green infrastructure for stormwater management and local temperature regulation, in particular, exhibited great alignment with wildlife crossing and ecological connectivity objectives, demonstrating how vegetated wildlife crossings and corridors can serve multiple purposes (Lister 2014, 2015). Continuing to interrogate these areas of convergence using an analytical framework such as ICBF can further illuminate co-benefit opportunities such as those related to smart and effective infrastructure and nature-based solutions design. For example, incorporating drought-resilient and pollinator-supportive plants in vegetated crossing structures could contribute to climate action, food systems, and biodiversity objectives (Reynolds et al. 2020).

Uncovering potential trade-offs is equally important as understanding co-benefits (Ürge-Vorsatz et al. 2014, Newell et al. 2018, Choi et al. 2021). Our research revealed potential conflicts in integrating climate, biodiversity, and wildlife crossing and landscape connectivity strategies, in particular, those associated with large-scale energy-focused climate action. Sustainable and resilient energy production consists of distributed, renewable energy systems that contribute both to energy security and to greenhouse gas emissions reductions (O'Brien and Hope 2010, Schwanitz et al. 2015, Bollinger et al. 2018); however, as we observed, these types of large-scale systems can lead to significant habitat fragmentation through the development of service roads for energy infrastructure. This trade-off was examined in the specific context of wind energy, but the finding has broader implications for integrated climate-biodiversity planning because it is a potential conflict for a number of different types of decentralized and distributed energy systems. Therefore, effective integrated planning requires strategic placement of appropriately scaled energy infrastructure to minimize habitat and biodiversity impacts.

Not only did the ICBF analysis illuminate potential co-benefits and trade-offs, it revealed problems with current approaches to wildlife crossing planning and needs for policy and regulatory changes. In particular, the data revealed that wildlife crossing strategies often employ a single-species approach in which the development of crossing infrastructure is triggered by the presence of a species-at-risk (e.g., usually an iconic or charismatic mammal for overpass structures, and a herptile species-at-risk for underpasses and culvert crossings). Such an approach can obscure the value of habitats that support common yet important species such as migratory and breeding birds or insectivores that provide critical pest management services (Ürge-Vorsatz et al. 2014, Reynolds et al. 2020). In addition, single-species foci do not account for green space contributions to climate objectives such as flood control, water conservation and regulation, and local temperature regulation (Raymond et al. 2017, Spencer et al. 2017). Although protecting species-at-risk is important for biodiversity conservation, an integrated approach would involve a more holistic understanding of different habitats and their various functions for supporting both climate action and biodiversity (Onaindia et al. 2013, Sollmann et al. 2017, Hilty et al. 2019).

The application of ICBF was valuable for providing new perspectives and ways of thinking about wildlife crossing strategies and landscape connectivity issues, as well as specific planning and design approaches. The analysis revealed how wildlife crossing planning is primarily approached in terms of minimizing and mitigating wildlife mortality in the face of increasing vehicle traffic and expanding road networks. In contrast, an integrated climate-biodiversity perspective shifts attention toward the problem at its source, that is, reducing traffic and controlling road expansion. In many ways, this insight captures a fundamental problem with the state of wildlife crossing practices in North America, where the focus is on human safety and traffic flow rather than biodiversity conservation and ecosystem integrity. Other research has confirmed this result: Practitioners have described wildlife crossing needs and goals treated as subordinate to transportation planning (Newell et al. $2020 a$ ), and crossing infrastructure is more likely to be funded if it is included as a part of a larger road development project (Huisjer et al. 2008, Elton and Dreschner 2019). An integrated approach to wildlife crossing efforts would incorporate long-term planning and recognize sustainable imperatives around traffic reduction and optimal scale of transportation networks, which are particularly critical considerations in light of the fact that wildlife migration patterns will shift as the climate changes (Lister et al. 2015, Hilty et al. 2019).

Integrated analysis was not only useful for elucidating important challenges and opportunities for wildlife crossings and landscape connectivity, but it also expanded the scope of the field by introducing new ideas and considerations for both policy direction and planning action in this emerging area of research and practice. For example, the ICBF systems map illustrates how effective wildfire management can produce climate and biodiversity co-benefits related to protecting carbon sinks and wildlife habitat (Green and Minchin 2012). Accordingly, although absent from the data, managing wildfire risks in key ecological corridors can serve as an important connectivity strategy while producing climate, health, and public safety co-benefits. An integrated perspective can stimulate thinking about broader considerations related to landscape connectivity objectives, as well as key partnerships and interdepartment and interagency bridges for designing and implementing best-and-next practices and policies in the context of place and community. 
A limitation of our study is that the interview data were from a larger research project, Safe Passage, and were collected prior to developing the analytical framework. Being focused on wildlife crossings, the Safe Passage participant selection primarily included those working in the areas of transportation infrastructure, landscape connectivity, parks and protected areas, biodiversity conservation, and planning. Perhaps engaging people who work in the fields of agriculture and energy would result in richer insights in those areas of analysis. In addition, although ICBF includes a multitude of relationships, linkages between climate action and biodiversity conservation are plentiful and complex, and the framework does not cover their entirety. Future research could improve and refine the framework by adding new factors and linkages such as the effects of biochar on soil microbial biodiversity (Li et al. 2020) and the relationships among strategies aimed at minimizing wildlife impacts and reducing energy consumption when addressing light pollution (Falchi et al. 2011). We included a nodes and relationships table (Appendix 1) and the systems map (Appendix 2), and we invite researchers and practitioners to refine and alter the framework to adapt and use it for their own purposes.

In addition to limitations around the research data and scope, another area where this work could be improved is through stronger incorporation of social and cultural considerations. We developed ICBF based on the assumption that biodiversity conservation and climate action are necessary for the well-being of humans and the environment, but we recognize that the benefits and co-benefits of biodiversity and climate strategies are not enjoyed equally by all members of a community. As an example, Agyeman (2014) discusses a park in Bristol that was developed with a "wild" aesthetic and tall grasses, and although many people liked the park, the local Asian and African Caribbean communities were uneasy in the space because of memories of and experiences with venomous snakes in tall grasses in their birth countries. Future work could further develop and evolve the framework to incorporate concepts and objectives for social and cultural aspects of a community or region, such as those identified by Dempsey et al.'s (2011) work on the dimensions of social sustainability, which include social equity and justice.

\section{CONCLUSION}

Our research demonstrates the importance of employing an integrated perspective when investigating ways of improving both policy and planning. Such a perspective can highlight the challenges, opportunities, co-benefits, and trade-offs that would otherwise be obscured, and can elucidate cost-benefit trade-offs. Demonstrating the co-benefits of any one action is critical for understanding its broader role in sustainable development, and it provides rationale for securing additional funding for further actions in competing government agendas and land-use decisions. Although we focused on wildlife crossings and landscape connectivity, ICBF can be applied to a number of different local, regional, and global issues such as economic development, community revitalization, urban growth, or waste management. Ultimately, it is a tool for understanding how policy and planning can best align with climate change and biodiversity objectives, recognizing that these are among the most critical sustainability issues facing the planet (Rockström et al. 2009, Steffen et al. 2015, IPCC 2018, IPBES 2019). ICBF is a novel framework with potential for further development, and future research can refine it to better capture nuances and relationships in integrated planning and policy. Ultimately, continual use and refinement of such frameworks will result in valuable research tools and associated practices for better understanding how to transition effectively toward sustainable development paths.

Responses to this article can be read online at: https://www.ecologyandsociety.org/issues/responses. php/12999

\section{Acknowledgments:}

We gratefully acknowledge the support for this research provided by the Social Sciences and Humanities Research Council of Canada (SSHRC) through its Partnership Development Grants program. We acknowledge the research assistants and participants who contributed to the Safe Passage project, upon which this study builds.

\section{Data Availability:}

In accordance with ethical approval granted by Ryerson University's Research Ethics Board, interview data are not publicly available because they contain information that could compromise the privacy of research participants. Data used to develop the systems map are available in Appendix 1: list nodes, node types, relationships, and relationship types. The working file of the systems map (prepared using yEd Graph Editor v. 3.17.2) is available in Appendix 2.

\section{LITERATURE CITED}

Aasness, M. A., and J. Odeck. 2015. The increase of electric vehicle usage in Norway-incentives and adverse effects. European Transport Research Review 7:34. https://doi. org/10.1007/s12544-015-0182-4

Agyeman, J. 2014. Entering cosmopolis: crossingover, hybridity, conciliation, and the intercultural city ecosystem. Minding Nature 7(1):20-25. [online] URL: https://www.humansandnature. org/entering-cosmopolis-crossingover-hybridity-conciliation-andthe-intercultural-city-ecosystem-by-julian-agyeman

Bain, P. G., T. L. Milfont, Y. Kashima, M. Bilewicz, G. Doron, R. B. Garðarsdóttir, V. V. Gouveia, Y. Guan, L.-O. Johansson, C. Pasquali, V. Corral-Verdugo, J. I. Aragones, A. Utsugi, C. Demarque, S. Otto, J. Park, M. Soland, L. Steg, R. González, N. Lebedeva, O. J. Madsen, C. Wagner, C. S. Akotia, T. Kurz, J. L. Saiz, P. W. Schultz, G. Einarsdóttir, and N. M. Saviolidis. 2016. Co-benefits of addressing climate change can motivate action around the world. Nature Climate Change 6:154-157. https://doi. org/10.1038/nclimate2814

Beck, M. B., and R. Villarroel Walker. 2013. On water security, sustainability, and the water-food-energy-climate nexus. Frontiers of Environmental Science and Engineering 7:626-639. https://doi. org/10.1007/s11783-013-0548-6

Beckmann, J. P., A. P. Clevenger, M. P. Huijser, and J. A. Hilty, editors. 2010. Safe passages: highways, wildlife, and habitat connectivity. Island Press, Washington, D.C., USA. 
Bell, M., D. Fick, R. Ament, and N.-M. Lister. 2020. The use of fiber-reinforced polymers in wildlife-crossing infrastructure. Sustainability 12(4):1557. https://doi.org/10.3390/su12041557

Bollinger, L. A., C. B. Davis, R. Evins, E. J. L. Chappin, and I. Nikolic. 2018. Multi-model ecologies for shaping future energy systems: design patterns and development paths. Renewable and Sustainable Energy Reviews 82(part 3):3441-3451. https://doi. org/10.1016/j.rser.2017.10.047

Bowler, D. E., L. Buyung-Ali, T. M. Knight, and A. S. Pullin. 2010. Urban greening to cool towns and cities: a systematic review of the empirical evidence. Landscape and Urban Planning 97 (3):147-155. https://doi.org/10.1016/j.landurbplan.2010.05.006

Bustamante, M., C. Robledo-Abad, R. Harper, C. Mbow, N. H. Ravindranat, F. Sperling, H. Haberl, A. de Siqueira Pinto, and P. Smith. 2014. Co-benefits, trade-offs, barriers and policies for greenhouse gas mitigation in the agriculture, forestry and other land use (AFOLU) sector. Global Change Biology 20 (10):3270-3290. https://doi.org/10.1111/gcb.12591

Cairns, R., and A. Krzywoszynska. 2016. Anatomy of a buzzword: the emergence of 'the water-energy-food nexus' in UK natural resource debates. Environmental Science and Policy 64:164-170. https://doi.org/10.1016/j.envsci.2016.07.007

Chan, K. M. A., L. Hoshizaki, and B. Klinkenberg. 2011. Ecosystem services in conservation planning: targeted benefits vs. co-benefits or costs? Plos One 6(9):e24378. https://doi. org/10.1371/journal.pone.0024378

Choi, C., P. Berry, and A. Smith. 2021. The climate benefits, cobenefits, and trade-offs of green infrastructure: a systematic literature review. Journal of Environmental Management 291:112583. https://doi.org/10.1016/j.jenvman.2021.112583

City of Edmonton. 2016. Breathe: Edmonton's green network strategy. City of Edmonton, Edmonton, Canada. [online] URL: https://www.edmonton.ca/public-files/assets/document?path=PDF/ EdmontonGreenNetworkContext_Stage1SummaryReport July2016. pdf

Clevenger, A. P., and M. Barrueto, editors. 2014. Trans-Canada Highway wildlife and monitoring research: final report 2014. Part B: research. Prepared for Parks Canada Agency, Radium Hot Springs, Canada. [online] URL: https://arc-solutions.org/wpcontent/uploads/2015/12/Banff-TCH-Wildlife-Monitoring-ResearchFinal-Report-2014 withappendices1.pdf

Clevenger, A. P., and N. Waltho. 2005. Performance indices to identify attributes of highway crossing structures facilitating movement of large mammals. Biological Conservation 121 (3):453-464. https://doi.org/10.1016/j.biocon.2004.04.025

Colléony, A., and A. Shwartz. 2019. Beyond assuming co-benefits in nature-based solutions: a human-centered approach to optimize social and ecological outcomes for advancing sustainable urban planning. Sustainability 11(18):4924. https:// doi.org/10.3390/su11184924

Collier, M. J., Z. Nedović-Budić, J. Aerts, S. Connop, D. Foley, K. Foley, K., D. Newport, S. McQuaid, A. Slaev, and P. Verburg. 2013. Transitioning to resilience and sustainability in urban communities. Cities 32(S1):S21-S28. https://doi.org/10.1016/j. cities.2013.03.010
Dale, A. 2001. At the edge: sustainable development in the 21st century. UBC Press, Vancouver, Canada.

Dale, A., S. Burch, J. Robinson, and C. Strashok. 2018. Multilevel governance of sustainability transitions in Canada: policy alignment, innovation, and evaluation. Pages 343-358 in S. Hughes, E. K. Chu, and S. G. Mason, editors. Climate change in cities: innovations in multi-level governance. Springer, Cham, Switzerland. https://doi.org/10.1007/978-3-319-65003-6 17

Dempsey, N., G. Bramley, S. Power, and C. Brown. 2011. The social dimension of sustainable development: defining urban social sustainability. Sustainable Development 19(5):289-300. https://doi.org/10.1002/sd.417

Elton, K., and M. Drescher. 2019. Implementing wildlifemanagement strategies into road infrastructure in southern Ontario: a critical success factors approach. Journal of Environmental Planning and Management 62(5):862-880. https:// doi.org/10.1080/09640568.2018.1447445

Environment Canada. 2013. How much habitat is enough? Third edition. Environment Canda, Toronto, Canada. [online] URL: https://www.documentcloud.org/documents/2999368-THUNDERBAY-How-Much-Habitat-Is-Enough-3rd-Ed-2013.html

Falchi, F., P. Cinzano, C. D. Elvidge, D. M. Keith, and A. Haim. 2011. Limiting the impact of light pollution on human health, environment and stellar visibility. Journal of Environmental Management 92(10):2714-2722. https://doi.org/10.1016/j. jenvman.2011.06.029

Galderisi, A. 2017. Nexus approach to disaster risk reduction, climate adaptation and ecosystems' management: new paths for a sustainable and resilient urban development. Pages 11-21 in A. Colucci, M. Magoni, and S. Menoni, editors. Peri-urban areas and food-energy-water nexus: sustainability and resilience strategies in the age of climate change. Springer, Cham, Switzerland. https://doi.org/10.1007/978-3-319-41022-7_2

Gibbs, G. 2007. Analyzing qualitative data. Sage Publications, London, UK. https://dx.doi.org/10.4135/9781849208574

Green, D., and L. Minchin. 2012. The co-benefits of carbon management on country. Nature Climate Change 2:641-643. https://doi.org/10.1038/nclimate1643

Hellegers, P., D. Zilberman, P. Steduto, and P. McCornick. 2008. Interactions between water, energy, food and environment: evolving perspectives and policy issues. Water Policy 10(S1):1-10. https://doi.org/10.2166/wp.2008.048

Heller, N. E., and E. S. Zavaleta. 2009. Biodiversity management in the face of climate change: a review of 22 years of recommendations. Biological Conservation 142(1):14-32. https:// doi.org/10.1016/j.biocon.2008.10.006

Hilty, J. A., A. T. H. Keeley, W. Z. Lidicker Jr., and A. M. Merenlender. 2019. Corridor ecology: linking landscapes for biodiversity conservation and climate adaptation. Second edition. Island Press, Washington, D.C., USA.

Hilty, J., G. L. Worboys, A. Keeley, S. Woodley, B. J. Lausche, H. Locke, M. Carr, I. Pulsford, J. Pittock, J. W. White, D. M. Theobald, J. Levine, M. Reuling, J. E. M. Watson, R. Ament, C. Groves, and G. M. Tabor. 2020. Guidelines for conserving connectivity through ecological networks and corridors. IUCN 
Best Practice Protected Area Guidelines Series 30. International Union for Conservation of Nature, Gland, Switzerland. https:// doi.org/10.2305/IUCN.CH.2020.PAG.30.en

Hoff, H. 2011. Understanding the nexus. Background paper for the Bonn2011 conference: The Water, Energy and Food Security Nexus. Stockholm Environment Institute, Stockholm, Sweden. [online] URL: https://www.sei.org/publications/understandingthe-nexus/

Houghton, A., and C. Castillo-Salgado. 2017. Health co-benefits of green building design strategies and community resilience to urban flooding: a systematic review of the evidence. International Journal of Environmental Research and Public Health 14 (12):1519. https://doi.org/10.3390/ijerph14121519

Intergovernmental Panel on Climate Change (IPCC). (2018). Global warming of $1.5^{\circ} \mathrm{C}$. An IPCC Special Report on the impacts of global warming of $1.5^{\circ} \mathrm{C}$ above pre-industrial levels and related global greenhouse gas emission pathways, in the context of strengthening the global response to the threat of climate change, sustainable development, and efforts to eradicate poverty. V. Masson-Delmotte, P. Zhai, H.-O. Pörtner, D. Roberts, J. Skea, P. R. Shukla, A. Pirani, W. Moufouma-Okia, C. Péan, R. Pidcock, S. Connors, J. B. R. Matthews, Y. Chen, X. Zhou, M. I. Gomis, E. Lonnoy, T. Maycock, M. Tignor, and T. Waterfield, editors. IPCC, Geneva, Switzerland. [online] URL: https://www. ipcc.ch/sr15/

Intergovernmental Science-Policy Platform on Biodiversity and Ecosystem Services (IPBES). 2019. Global assessment report on biodiversity and ecosystem services. E. S. Brondizio, J. Settele, S. Díaz, and H. T. Ngo, editors. IPBES Secretariat, Bonn, Germany. https://doi.org/10.5281/zenodo.3831673

Jakeman, A. J., and R. A. Letcher. 2003. Integrated assessment and modelling: features, principles and examples for catchment management. Environmental Modelling and Software 18 (6):491-501. https://doi.org/10.1016/S1364-8152(03)00024-0

Karlsson, M., E. Alfredsson, and N. Westling. 2020. Climate policy co-benefits: a review. Climate Policy 20(3):292-316. https:// doi.org/10.1080/14693062.2020.1724070

Kelly (Letcher), R. A., A. J. Jakeman, O. Barreteau, M. E. Borsuk, S. ElSawah, S. H. Hamilton, H. J. Henriksen, S. Kuikka, H. R. Maier, A. E. Rizzoli, H. van Delden, and A. A. Voinov. 2013. Selecting among five common modelling approaches for integrated environmental assessment and management. Environmental Modelling and Software 47:159-181. https://doi. org/10.1016/j.envsoft.2013.05.005

Li, X., T. Wang, S. X. Chang, X. Jiang, and Y. Song. 2020. Biochar increases soil microbial biomass but has variable effects on microbial diversity: a meta-analysis. Science of the Total Environment 749:141593. https://doi.org/10.1016/j.scitotenv.2020.141593

Ling, C., K. Hanna, and A. Dale. 2009. A template for integrated community sustainability planning. Environmental Management 44(2):228-242. https://doi.org/10.1007/s00267-009-9315-7

Lister, N.-M. E. 2014. Crossing the road, raising the bar: the ARC international design competition. Ecological Restoration 30 (4):335-340. https://doi.org/10.3368/er.30.4.335
Lister, N.-M. 2015. New infrastructure for landscape connectivity. LA+ Interdisciplinary Journal of Landscape Architecture (1):44-53.

Lister, N.-M., M. Brocki, and R. Ament. 2015. Integrated adaptive design for wildlife movement under climate change. Frontiers in Ecology and the Environment 13(9):493-502. https:// doi.org/10.1890/150080

Mawdsley, J. R., R. O'Malley, and D. S. Ojima. 2009. A review of climate-change adaptation strategies for wildlife management and biodiversity conservation. Conservation Biology 23 (5):1080-1089.https://doi.org/10.1111/j.1523-1739.2009.01264.X

Mayrhofer, J. P., and J. Gupta. 2016. The science and politics of co-benefits in climate policy. Environmental Science and Policy 57:22-30. https://doi.org/10.1016/j.envsci.2015.11.005

Milner, J., M. Davies, and P. Wilkinson. 2012. Urban energy, carbon management (low carbon cities) and co-benefits for human health. Current Opinion in Environmental Sustainability 4(4):398-404. https://doi.org/10.1016/j.cosust.2012.09.011

Newell, R., A. Dale, and M. Roseland. 2018. Climate action cobenefits and integrated community planning: uncovering the synergies and trade-offs. International Journal of Climate Change: Impacts and Responses 10(4):1-23. https://doi. org/10.18848/1835-7156/CGP/v10i04/1-23

Newell, R., N.-M. Lister, and A. Dale. 2020a. Wildlife crossing database platform: description of the tool and summary of researcher/practitioner feedback. Self-published technical report. https://doi.org/10.13140/RG.2.2.36354.09925

Newell, R., and I. Picketts. 2020. Spaces, places and possibilities: a participatory approach for developing and using integrated models for community planning. City and Environment Interactions 6:100040. https://doi.org/10.1016/j.cacint.2020.100040

Newell, R., I. Picketts, and A. Dale. 2020b. Community systems models and development scenarios for integrated planning: lessons learned from a participatory approach. Community Development 51(3):261-282. https://doi.org/10.1080/15575330.2$\underline{020.1772334}$

O'Brien, G., and A. Hope. 2010. Localism and energy: negotiating approaches to embedding resilience in energy systems. Energy Policy 38(12):7550-7558. https://doi.org/10.1016/j.enpol.2010.03.033

Oliveira, S., H. Andrade, and T. Vaz. 2011. The cooling effect of green spaces as a contribution to the mitigation of urban heat: a case study in Lisbon. Building and Environment 46 (11):2186-2194. https://doi.org/10.1016/j.buildenv.2011.04.034

Onaindia, M., B. Fernández de Manuel, I. Madariaga, and G. Rodríguez-Loinaz. 2013. Co-benefits and trade-offs between biodiversity, carbon storage and water flow regulation. Forest Ecology and Management 289:1-9. https://doi.org/10.1016/j. foreco.2012.10.010

Phelps, J., E. L. Webb, and W. M. Adams. 2012. Biodiversity cobenefits of policies to reduce forest-carbon emissions. Nature Climate Change 2:497-503. https://doi.org/10.1038/nclimate1462 
Raymond, C. M., N. Frantzeskaki, N. Kabisch, P. Berry, M. Breil, M. R. Nita, D. Geneletti, and C. Calfapietra. 2017. A framework for assessing and implementing the co-benefits of nature-based solutions in urban areas. Environmental Science and Policy 77:15-24. https://doi.org/10.1016/j.envsci.2017.07.008

Reynolds, H. L., L. Brandt, B. C. Fischer, B. S. Hardiman, D. J. Moxley, E. Sandweiss, J. H. Speer, and S. Fei. 2020. Implications of climate change for managing urban green infrastructure: an Indiana, US case study. Climatic Change 163:1967-1984. https:// doi.org/10.1007/s10584-019-02617-0

Riley, S. P. D., T. Smith, and T. W. Vickers. 2018. Assessment of wildlife crossing sites for the Interstate 15 and Highway 101 freeways in southern California. National Park Service, Twentynine Palms, and The Nature Conservancy, San Francisco, California, USA. [online] URL: https://www.nps.gov/samo/learn/ news/upload/SAM SMM Final-Linkage-Report final 031218compliant-1.pdf

Robinson, J. M., and M. F. Breed. 2019. Green prescriptions and their co-benefits: integrative strategies for public and environmental health. Challenges 10(1):9. https://doi.org/10.3390/ challe10010009

Rockström, J., W. Steffen, Kevin Noone, Å. Persson, F. S. Chapin III, E. F. Lambin, T. M. Lenton, M. Scheffer, C. Folke, H. J. Schellnhuber, B. Nykvist, C. A. de Wit, T. Hughes, S. van der Leeuw, H. Rodhe, S. Sörlin, P. K. Snyder, R. Costanza, U. Svedin, M. Falkenmark, L. Karlberg, R. W. Corell, V. J. Fabry, J. Hansen, B. Walker, D. Liverman, K. Richardson, P. Crutzen, and J. A. Foley. 2009. A safe operating space for humanity. Nature 461:472-475. https://doi.org/10.1038/461472a

Ronggui, H. 2016. RQDA: R-based qualitative data analysis. R package version 0.2-8. [online] URL: http://rqda.r-forge.rproject.org/

Rosenzweig, C., W. Solecki, L. Parshall, S. Gaffin, B. Lynn, R. Goldberg, J. Cox, and S. Hodges. 2006. Mitigating New York City's heat island with urban forestry, living roofs, and light surfaces. Unpublished project report to the New York State Energy Research and Development Authority. [online] URL: https://www.giss.nasa.gov/research/news/20060130/103341.pdf

Rydin, Y. 2010. Governing for sustainable urban development. Earthscan, London, UK. https://doi.org/10.4324/9781849775083

Saidur, R., N. A. Rahim, M. R. Islam, and K. H. Solangi. 2011. Environmental impact of wind energy. Renewable and Sustainable Energy Reviews 15(5):2423-2430. https://doi. org/10.1016/j.rser.2011.02.024

Saldaña, J. 2009. The coding manual for qualitative researchers. Sage, Thousand Oaks, California, USA.

Santamouris, M. 2014. Cooling the cities - a review of reflective and green roof mitigation technologies to fight heat island and improve comfort in urban environments. Solar Energy 103:682-703. https://doi.org/10.1016/i.solener.2012.07.003

Schwanitz, V. J., T. Longden, B. Knopf, and P. Capros. 2015. The implications of initiating immediate climate change mitigation - a potential for co-benefits? Technological Forecasting and Social Change 90(part A):166-177. https://doi.org/10.1016/j.techfore.2014.01.003

Seidel, J., and U. Kelle. 1995. Different functions of coding in the analysis of textual data. Pages 52-61 in U. Kelle, editor. Computeraided qualitative data analysis: theory, methods and practice. Sage, Thousand Oaks, California, USA.

Sharifi, A. 2021. Co-benefits and synergies between urban climate change mitigation and adaptation measures: a literature review. Science of the Total Environment 750:141642. https://doi. org/10.1016/j.scitotenv.2020.141642

Shaw, A., S. Burch, F. Kristensen, J. Robinson, and A. Dale. 2014. Accelerating the sustainability transition: exploring synergies between adaptation and mitigation in British Columbian communities. Global Environmental Change 25:41-51. https:// doi.org/10.1016/j.gloenvcha.2014.01.002

Sollmann, R., A. Mohamed, J. Niedballa, J. Bender, L. Ambu, P. Lagan, S. Mannan, R. C. Ong, A. Langner, B. Gardner, and A. Wilting. 2017. Quantifying mammal biodiversity co-benefits in certified tropical forests. Diversity and Distributions 23 (3):317-328. https://doi.org/10.1111/ddi.12530

Sorensen, J. 1997. National and international efforts at integrated coastal management: definitions, achievements, and lessons. Coastal Management 25(1):3-41. https://doi.org/10.1080/08920$\underline{759709362308}$

Spencer, B., J. Lawler, C. Lowe, L. Thompson, T. Hinckley, S.-H. Kim, S. Bolton, S. Meschke, J. D. Olden, and J. Voss. 2017. Case studies in co-benefits approaches to climate change mitigation and adaptation. Journal of Environmental Planning and Management 60(4):647-667. https://doi.org/10.1080/09640568.2$\underline{016.1168287}$

Steffen, W., K. Richardson, J. Rockström, S. E. Cornell, I. Fetzer, E. M. Bennett, R. Biggs, S. R. Carpenter, W. de Vries, C. A. de Wit, C. Folke, D. Gerten, J. Heinke, G. M. Mace, L. M. Persson, V. Ramanathan, B. Reyers, and S. Sörlin. 2015. Planetary boundaries: guiding human development on a changing planet. Science 347(6223):1259855. https://doi.org/10.1126/science.1259855

Thomas, D. R. 2006. A general inductive approach for analyzing qualitative evaluation data. American Journal of Evaluation 27 (2):237-246. https://doi.org/10.1177/1098214005283748

Turner, K. G., M. V. Odgaard, P. K. Bøcher, T. Dalgaard, and J.C. Svenning. 2014. Bundling ecosystem services in Denmark: trade-offs and synergies in a cultural landscape. Landscape and Urban Planning 125:89-104. https://doi.org/10.1016/j.

landurbplan.2014.02.007

Ürge-Vorsatz, D., S. T. Herrero, N. K. Dubash, and F. Lecocq. 2014. Measuring the co-benefits of climate change mitigation. Annual Review of Environment and Resources 39:549-582. https://doi.org/10.1146/annurev-environ-031312-125456

van der Hel, S. 2016. New science for global sustainability? The institutionalisation of knowledge co-production in Future Earth. Environmental Science and Policy 61:165-175. https://doi. org/10.1016/j.envsci.2016.03.012 
Wang, L., F. Zhang, E. Pilot, J. Yu, C. Nie, J. Holdaway, L. Yang, Y. Li, W. Wang, S. Vardoulakis, and T. Krafft. 2018. Taking action on air pollution control in the Beijing-Tianjin-Hebei (BTH) region: progress, challenges and opportunities. International Journal of Environmental Research and Public Health 15(2):306. https://doi.org/10.3390/ijerph15020306 
Appendix 1. Table of co-benefit and trade-off relationships within the integrated climate-biodiversity framework

Please click here to download file 'appendix1.xlsx'. 
Ecology and Society 27(1): 23

https://www.ecologyandsociety.org/vol27/iss1/art23/

Appendix 2. Working project (yEd Graph Editor) of the integrated climate-biodiversity framework systems map

Please click here to download file 'appendix2.zip'. 